\title{
Molecular cues to the anti-implantation effect of nano-puerarin in rats
}

\author{
Ghungroo Saraswat ${ }^{1}$, Rajdeep Guha ${ }^{2}$, Kalyani Mondal ${ }^{1}$, Piyali Saha ${ }^{1,3}$, Sayani Banerjee ${ }^{1,4}$, \\ Prarthana Chakraborty ${ }^{1}$, Aditya Konar ${ }^{2}$ and Syed N Kabir ${ }^{1}$ \\ ${ }^{1}$ Reproductive Biology Research, CSIR-Indian Institute of Chemical Biology, Jadavpur, Kolkata, \\ West Bengal, India, ${ }^{2}$ Laboratory Animal Science, CSIR-Indian Institute of Chemical Biology, Jadavpur, Kolkata, \\ West Bengal, India, ${ }^{3}$ Department of Biological Sciences and Bioengineering, Indian Institute of Technology, Kanpur, \\ Uttar Pradesh, India, and ${ }^{4}$ Department of Biological Sciences, Ohio University, Ohio, USA
}

Correspondence should be addressed to S N Kabir; Email: snkabir@iicb.res.in; sdnkabir@gmail.com

\begin{abstract}
Puerarin, a selective oestrogen receptor modulator, intercepts implantation in rats, albeit at unacceptably higher doses. We developed poly lactic-co-glycolic acid-encapsulated nano-puerarin (PN) and mapped the molecular pathway underlying its anti-implantation effects. Smooth-surfaced and spherical PN having a mean diameter of $\sim 147$ nm was obtained with good yield, efficient encapsulation, and optimum drug loading. In culture, PN slowly and steadily released puerarin, which was readily taken up by the decidual cells. PN exerted a dose-dependent anti-implantation effect. As marked by attenuated expression of stromal cell desmin, alkaline phosphatase, IGFBP1, and decidual prolactin-related protein, the anti-implantation effect of PN seemed secondary to compromised decidualization. Using in vivo (pregnant and pseudopregnant rats) and in vitro (endometrial stromal cell culture) treatment models, we document that PN enforced inhibition of uterine expression of Hbegf and Hoxa10 and their downstream signalling molecules, Cyclin D3 (CCND3)/CDK4. PN also efficiently ablated the Ihh-Nr2f2-Bmp2 signalling pathway and invited the loss of uterine potential for decidualization. There was a dose-dependent up-regulation of RHOA and its effector protein kinase, ROCK1, leading to the promotion of MLC phosphorylation and actin-myosin interaction. PN also down-regulated the stromal cell activation of ERK $1 \frac{1}{2}$ and expression of MMP9. These effects acting together stabilized the stroma and inhibited the stromal cell migration. Central to this array of events was the adversely altered endometrial expression of oestrogen receptor subtypes and repression of progesterone receptor that indulged endless proliferation of luminal epithelia and distorted the precisely choreographed stroma-epithelia crosstalk. Thus, PN dismantles the endometrial bed preparation and prevents implantation. Reproduction (2016) 151 693-707
\end{abstract}

\section{Introduction}

Unintended pregnancy and population explosion is a significant global health care problem. Oral contraceptives, including emergency contraceptive (EC) implants and injectables, intrauterine devices and barrier methods, are birth control options available to overcome this burden (Cullwell \& Curtis 2009). Post-coital or EC is a popular form of reversible contraception option to prevent pregnancy. Oestrogens and progestins, individually or in combination, and antiprogestins form the active constituents of the currently available major hormonal EC formulations (Farrar et al. 2003), but they have some undesirable side effects largely attributable to their oestrogen content (Dvorák \& Bocan 1980). Development of a safe and effective non-steroidal contraceptive formulation is, therefore, recognized as a global need today.

EC may prevent pregnancy by delaying or suppressing ovulation, inhibiting fertilization or impairing endometrial receptivity to implantation of a fertilized egg (Ling et al. 1979). Implantation is the crucial step in the process of establishment of pregnancy; rat uterus undergoes profound changes in response to blastocyst implantation during pregnancy, or to an artificial stimulus during pseudopregnancy (PS) (Tessier et al. 2000). This reaction coincides with decidualization at the site of the implanting blastocyst (Das 2009). This process of blastocyst implantation involves the participation of oestrogen to a significant extent (Psychoyos 1973). Oestrogens act by binding to and activating oestrogen receptors (ERs) and exert their effects through diverse signalling pathways resulting in tissue-specific responses (Marino et al. 2006). The structure of the ligand and the ER subtype determine the intriguing biology of oestrogens on different target cells. In many tissues including the uterus, oestrogen receptor alpha (ESR1 or ER $\alpha$ ) mediates the proliferative effects, while oestrogen receptor beta (ESR2 or ER $\beta$ ) mediates antiproliferative effects (Marino \& Galluzzo 
2008). Along with this genomic action, oestradiol $\left(E_{2}\right)$ binding to ERs also induced rapid signalling, such as ESR1- $\mathrm{E}_{2}$ complex interactions with the insulin-like growth factor 1(IGF1) or epidermal growth factor (EGF) receptor leading to activation of mitogen-activated protein kinase (MAPK) signalling pathway (Improta-Brears et al. 1999, Kahlert et al. 2000). ESR1 plays a significant role in the process of embryo implantation (Achache \& Revel 2006). The proliferative actions mediated through ESR1 attribute to major untoward effects of the oestrogenbased EC (Mendez 2002).

Phyto-oestrogens are naturally occurring plant compounds having various therapeutic applications, and also play a role in regulating fertility. It embodies several groups of non-steroidal oestrogen including isoflavones and lignans (Jefferson et al. 2012). Certain phyto-oestrogens have selective ER modulator (SERM)-like properties (Riggs \& Hartmann 2003) and are reported to possess abortifacient activity (Sylvestre et al. 2006). In this line of search, we have identified a plant Pueraria tuberose, whose ethanolic extract and the $\mathrm{n}-\mathrm{BuOH}$ fraction thereof are reported to have significant antifertility activity in rats, mice and hamsters, and possesses significant oestrogenic activity (Shukla 1996). These extracts have various compounds, and among them, puerarin fraction was found to be most effective (Shukla \& Mathur 2002). Our previous work reported that puerarin, an SERM, counteracts the proliferative action of oestrogen and disrupts embryo-uterine communication to inhibit implantation in the rat. Therefore, puerarin was proposed as a possible candidate molecule for the development of non-steroidal EC formulation (Saha et al. 2012). The future prospect of puerarin, however, seemed limited by its high minimum effective dose to induce 100\% implantation failure $\left(\mathrm{MED}_{100}\right)$ (Saha et al. 2012), reduced solubility, short elimination half-life and poor oral bioavailability (Yu et al. 2011). There is a need to develop a new oral delivery system to overcome the limitations of puerarin and enhance its overall effectiveness.

Nanoparticles (NP) hold tremendous potential as an efficient drug delivery system (Suri et al. 2007). NP-mediated drug delivery may be more efficient owing to the sustained release of the drug that prolongs the contact time with the target tissue(s). This system may also permit a reduction in the dose of the compound that has poor oral bioavailability. Zhao et al. (2013) reported that nano-puerarin $(\mathrm{PN})$ improves the oral absorption of puerarin. In this direction, this study aims to develop $\mathrm{PN}$, evaluate its anti-implantation efficacy, and map the molecular cues underlying the contragestive potential.

\section{Materials and methods}

\section{Chemicals}

Unless otherwise stated, chemicals used for the preparation of reagents were of analytical grade and purchased from SigmaAldrich. Goat polyclonal desmin (sc-7559), insulin-like growth factor-binding protein 1 (IGFBP1; sc- 6072), ESR2 (Sc-6821), rabbitpolyclonal cyclin D3 (CCND3; Sc-182), cyclin-dependent kinase (CDK)4 (sc-260), ESR1 (Sc-7207), progesterone receptor (PR; Sc-538), mouse monoclonal B-Actin (Sc-47778), mouse anti-goat $\lg$ secondary antibody fluorescein isothiocyanate (FITC; Sc-2356), goat anti-rabbit IgG secondary antibody-FITC (Sc-2012), donkey anti-rabbit IgG secondary antibody-HRP (Sc-2313), donkey anti-goat IgG secondary antibody-HRP (Sc2020) and goat anti-mouse IgG secondary antibody-HRP (Sc-2031) were obtained from Santa Cruz Biotechnology. Rabbit polyclonal p44/42 MAPK (ERK $1 / 2 ; \# 9102), p-p 44 / 42$ MAPK (pERK $\left.1 \frac{12}{2} ; \# 4370 p\right)$, myosin light chain (MLC; \#3672p), phospho-MLC (pMLC; \#3671p), rabbit monoclonal RAS homolog gene family, member A (RHOA; \#2117p) and Rho-associated protein kinase (ROCK; \#4035s) were obtained from Cell Signaling Technology. All other common chemicals including methanol $(\mathrm{MeOH})$, chloroform $\left(\mathrm{CHCl}_{3}\right)$, 2-amino-2-(hydroxymethyl)-1,3-propanediol hydrochloride (Tris- $\mathrm{HCl}$ ), sucrose, ethylene glycol tetraacetic acid, $\mathrm{KCl}$, $\mathrm{MgCl}_{2}$, dithiothreitol (DTT) and picric acid were obtained from Merck Specialities Pvt Ltd. (Darmstadt, Germany).

\section{Preparation of PN}

PN was prepared by solvent evaporation technique. In brief, poly lactic-co-glycolic acid (PLGA) (Sigma-Aldrich, cat \# P2191) and puerarin were dissolved in acetone. The mixture was added dropwise to a solution of $1 \%$ dodecyl dimethyl ammonium bromide (Sigma-Aldrich, cat \# 359025) and stirred gently on a magnetic stirrer at $350 \mathrm{rpm}$ until the acetone evaporated. After complete removal of the solvents, the PNs were collected by ultracentrifugation (Sorvall WX ULTRA90; Thermo Fisher Scientific) at $150,735 \mathrm{~g}$, washed twice with de-ionized water, lyophilized (Virtis; SP Scientific, PA, USA), and finally stored at $4^{\circ} \mathrm{C}$ until further use. Blank PLGA nanoparticles were prepared without using puerarin, and Nile red-labelled nanoparticles were prepared without puerarin and dissolving Nile red (Sigma-Aldrich, cat \#19123) in p-dimethylaminobenzaldehyde solution.

\section{Characterization of $P N$}

\section{Surface morphology}

The morphology of PN was analysed by transmission electron microscopy (TEM) and atomic force microscopy (AFM) as described earlier (Guha et al. 2013). For TEM, a drop of PN suspension $(1 \mathrm{mg} / \mathrm{mL})$ was placed onto a carbon film coated on a copper grid, stained with $1 \%$ uranyl acetate, air dried at room temperature and observed under TEM (Tecnai G2 Spirit BioTWIN; FEl, Brno-Kralovo Pole, Czech Republic). For AFM, a drop of PN suspension $(1 \mathrm{mg} / \mathrm{mL})$ was placed on a freshly cleaved muscovite ruby mica sheet (ASTMV1 grade ruby mica; MICAFAB, Chennai, India), air dried at room temperature. The observation was made and imaged using a PicoPlus 5500 ILM AFM (Agilent Technologies) in amplitude and tapping mode.

\section{Physicochemical properties}

The average particle size, size distribution and surface charge of PN were determined by dynamic light scattering 
(DLS) measurements (Malvern Zetasizer Nano ZS; Malvern Instruments, Malvern, UK) following the procedure described in the instrument manual. A solution of lyophilized PN (1 mg/ $\mathrm{mL}$ ) was used for the measurement. The intensity of the scattered light was detected at $90^{\circ}$ to an incident beam supplied by an argon laser. All measurements were done at $25^{\circ} \mathrm{C}$.

\section{In vitro release kinetics}

PN containing $250 \mu \mathrm{g}$ puerarin were dispersed in $1 \mathrm{~mL}$ phosphate-buffered saline (PBS) $(137 \mathrm{mM} \mathrm{NaCl}, 2.7 \mathrm{mM}$ $\mathrm{KCl}, 10 \mathrm{mM} \mathrm{Na} \mathrm{HPO}_{4}, 1.8 \mathrm{mM} \mathrm{KH} \mathrm{PO}_{4}, \mathrm{pH}$ 7.4) in each of the eight tubes and incubated at $37^{\circ} \mathrm{C}$ under constant stirring. At predetermined time points, the suspensions were centrifuged at $20,000 \mathrm{~g}$ for $30 \mathrm{~min}$ at room temperature and the concentration of puerarin in the supernatant was measured by HPLC. Twenty microlitres of the sample solution was injected into HPLC system for determination of puerarin in the supernatant. The analytical HPLC system (Shimadzu system, Japan) with column C18 (5 $\mu \mathrm{m}$, $4.6 \times 250 \mathrm{~mm}$, XTerra, Waters, MA, USA) was used. The mobile phase consisted of water:methanol:acetic acid at the volume ratio of 76:23:1 with the flow rate maintained at $1 \mathrm{~mL} / \mathrm{min}$. Signals were monitored at a fixed $\lambda_{\max }$ of $254 \mathrm{~nm}$.

The standard curve was prepared using a concentration range of $30-240 \mu \mathrm{g} / \mathrm{mL}$ of puerarin against the HPLC peak area and was used throughout for analysis. The equation relating to the peak area $(y)$ and PN concentration $(x)$ was $y=4.804 x$ and $r^{2}>0.981(r=$ correlation coefficient).

\section{Yield, encapsulation efficiency and drug loading}

The percentage yield of the $\mathrm{PN}$ was obtained using the equation:

$\%$ yield $=$ (weight of $\mathrm{PN}$ obtained/weight of puerarin and polymer used for $\mathrm{PN}$ preparation) $\times 100$

For the evaluation of encapsulation efficiency and puerarin loading, the amount of puerarin present in the supernatant following ultracentrifugation was quantified by HPLC as described above and was used to determine the encapsulation efficiency and drug loading using the following equations:

$$
\begin{aligned}
& \text { Puerarin }_{\text {entrapped }}=\text { Puerarin }_{\text {used }}-\text { Puerarin }_{\text {left in the supernatant }} \\
& \% \text { encapsulation }=\text { Puerarin }_{\text {entrapped }} / \text { Puerarin }_{\text {used }} \times 100 \\
& \text { Loading of puerarin }=\left(\text { Puerarin }_{\text {entrapped }} /(\text { polymer }+ \text { Puerarin })\right) \times 100
\end{aligned}
$$

\section{Cellular uptake}

The cellular uptake of PN by endometrial stromal cells was determined using Nile red-stained PLGA nanoparticles. The cultured cells were washed twice with PBS, re-suspended in culture media and incubated with Nile red-stained nanoparticle. At predetermined time points, the cells were washed, stained with DAPI (4',6-diamidino-2-phenylindole) and observed under fluorescence microscope (200x) (Carl Zeiss) for the presence of red color of Nile red within the cells.

\section{Animals}

Adult healthy female and male Sprague-Dawley rats (Rattus norvegicus, 180-220 g) were housed in controlled conditions of room temperature $\left(23 \pm 2{ }^{\circ} \mathrm{C}\right.$, humidity $(50 \pm 5 \%)$ and $12-\mathrm{h}$ light:12-h darkness cycle. The animals were kept in sanitized polypropylene cages and were fed with standard rat pellet diet and drinking water ad libitum. All experiments were performed as per the national guidelines formulated by the Committee for the Purpose of Care and Supervision of Experiments on Animals, India, with approval from the Animal Ethics Committee of Indian Institute of Chemical Biology (147/1999/ CPCSEA/SNK-P7/01-04-2011).

\section{Antifertility studies}

Cyclic female rats at proestrus phase were exposed overnight to proven fertile male rats. The day of noting the presence of sperm in the vaginal smear was considered day 1 (D1) of pregnancy. Pregnant rats were randomly distributed into four groups, each comprising 4-6 animals. They were orally administered either PN or void polymer dissolved in distilled water (control) at dose levels between 5 and $35 \mathrm{mg} / \mathrm{kg} /$ day from D1 to D4 of gestation. The animals were laparotomized on D9 of pregnancy under light ether anesthesia. The uteri were examined and photographed for the presence/absence of implantation sites. The rate of implantation (\%) was calculated as the number of implantation sites per functional corpus luteum (CL) present in the ovary (Hiremath et al. 2000) and plotted against each concentration of PN to construct a dose-response curve.

\section{Optimization of dose and duration}

The pregnant rats were treated with varying doses of $\mathrm{PN}$ for different lengths of the preimplantation phase of gestation and observed for $100 \%$ antifertility effect. Initially, treatment was at dose levels between 5 and $35 \mathrm{mg} / \mathrm{kg}$ per day for D1-D4. Subsequently, the dosage was increased gradually to $150 \mathrm{mg} /$ $\mathrm{kg}$ per day, while the duration of treatment was reduced to single-day administration (D1) (35-75 mg/kg/day for D1D3, $75-125 \mathrm{mg} / \mathrm{kg} /$ day for D1-D2, $125-150 \mathrm{mg} / \mathrm{kg} /$ day for D1). The total failure of pregnancy was considered as the target effect. The minimum dose administered for D1-D2 (75 mg/kg per day) that induced a complete loss of pregnancy was considered as the $\mathrm{MED}_{100}$; and further investigations were performed with this dose-and-duration regimen.

\section{Pseudopregnant rats and induction of decidualization}

Virgin female rats at the proestrus stage were exposed to vasectomized male rats and inspected for the presence of a vaginal plug the following morning. The day of finding vaginal plug was considered D1 of PS, which was further confirmed by persistent diestrus phase for at least four consecutive days. PS rats were allocated to four groups, each comprising 4-6 animals. On D4 of PS, rats were laparotomized under light ether anesthesia, and sesame seed oil $(25 \mu \mathrm{L})$ was infused into one uterine horn to stimulate decidual cell reaction while care was taken to avoid any mechanical trauma to the contralateral 
horn. A section of rats from each group was killed on D5 and D6 to evaluate the expression of different uterine markers of decidualization at the protein/mRNA level. The rest of the rats from both the groups were finally killed on day 8 when the uteri were dissected out, and the two horns were separated, cleaned of extra fat, and individually weighed. The magnitude of decidualization was assessed in terms of increase in weight of the traumatized uterine horn over that of the contralateral untreated horn.

\section{Isolation and culture of rat primary endometrial stromal cells}

Rat endometrial stromal cells ( $\mathrm{rESC}$ ) were isolated and collected from the uterine horns. In brief, the lumen of the uterine horn segments of the mature rats was filled with $0.1 \%$ collagenase in PBS and incubated at $37^{\circ} \mathrm{C}$ for $1 \mathrm{~h}$ for the isolation of stromal cells. Dulbecco's Modified Eagle's Medium and Ham's F-12 (1:1, v/v; DMEM/Ham's F-12; Cat \# 12500-062, Thermofisher Scientific) containing $10 \%$ heat-inactivated fetal bovine serum (FBS; cat \# 1008214, Thermofisher Scientific) and penicillinstreptomycin solution (cat \#15140-122, Thermofisher Scientific) was used as the principal culture medium. After centrifugation (1000 $\mathrm{g}$ for $3 \mathrm{~min}$ ) followed by washing and a medium change, the cells were suspended in the culture medium and plated onto 35-mm culture dishes. After a 30-min stromal attachment period, the medium was removed and replaced with a fresh medium to eliminate epithelial cells. Cell cultures were maintained at $37^{\circ} \mathrm{C}$ in humidified air with $5 \% \mathrm{CO}_{2}$ (Matsumoto et al. 2009). To study the effect on decidualization, the cells were cultured in the presence or absence of PN (1-5nM) for $24 \mathrm{~h}$ followed by culture for a further period of $72 \mathrm{~h}$ in the presence of medroxyprogesterone acetate (MPA) (100nM), db-cAMP (0.5 mM), and $E_{2}(10 n M)$. Finally, the cells were evaluated for alkaline phosphatase (ALP) activity and desmin expression.

\section{Isolation and separation of the rat endometrial epithelium and stroma}

Uterine luminal epithelial cells were isolated according to the method described in Bigsby et al. (1986). Briefly, pregnant rat uteri were isolated, cut into $1 \mathrm{~mm}$ segments and placed into $1 \%$ trypsin/ Hanks' balanced salt solution (HBSS; $\mathrm{Ca}^{+2}$-free, $\mathrm{Mg}^{2+}$-free) for $1.5 \mathrm{~h}$ at $4^{\circ} \mathrm{C}$, and then washed with cold HBSS. The uteri were placed into $20 \%$ FBS/HBSS solution for 5 min and washed with cold HBSS. The uterine luminal epithelium was gently removed from the uterine stroma under a dissecting microscope. Then, the remaining tissue samples were digested with $0.1 \%$ collagenase in HBSS. The tube was incubated for $60 \mathrm{~min}$ at $37^{\circ} \mathrm{C}$ for isolation of stromal cells. After washing by centrifugation, both epithelial and stromal cells were put in lysis buffer for western blotting analysis.

\section{Culture of human endometrial cell lines}

Human ESC (hESC) (ATCC CRL-4003) (Krikun et al. 2004) were grown in phenol red-free DMEM)/ F12 supplemented with 1\% ITS + Premix (Cat\# 354352, BD Biosciences, NJ, USA), 1\% penicillin/streptomycin solution and 10\% heat-inactivated FBS. For migration assay, endometrial stromal cells were cultured in the presence or absence of PN (1 nM and $5 \mathrm{nM}$ ) for $24 \mathrm{~h}$ followed by culture for a further period of $72 \mathrm{~h}$ in the presence of MPA (100 nM), db-cAMP $(0.5 \mathrm{mM})$, and $\mathrm{E}_{2}(10 \mathrm{nM})$ in phenol red-free DMEM/F12 supplemented with $2 \%$ FBS. The cultured cells were used to evaluate the effect of $\mathrm{PN}$ on the migration potential and the underlying signalling pathway.

\section{Alkaline phosphatase assay}

After oil infusion on D4, the PS uteri were removed on D5 and D6 from both treated and study group and washed with PBS. Tissues and primary cells were lysed with lysis buffer and protein content was determined by the method of Lowry et al. (1951) using bovine serum albumin as the standard. ALP activity was estimated using commercial assay kit (Cat\# 83360; Abchem, Cambridge, UK). This method is based on the ability of the enzyme to convert $p$-nitrophenyl phosphate to $p$-nitrophenol, which in an alkaline solution presents a yellow color and can be read at $405 \mathrm{~nm}$. The ALP activity $(\mathrm{U} / \mathrm{mL})$ of the test samples was calculated as $A / V / T$, where $A$ is the amount of $p$-nitrophenol generated by sample (in $\mu \mathrm{mol}$ ), $\mathrm{V}$ is the volume of sample added to the assay well (in $\mathrm{mL}$ ), and $\mathrm{T}$ is the reaction time in minute.

\section{Indirect immunofluorescence}

Immunofluorescence assessment of desmin was carried out in PS rat uteri fixed in 2-4\% paraformaldehyde (1-2 h at $4{ }^{\circ} \mathrm{C}$ ) and embedded in paraffin. Sections were mounted on poly-L-lysine-coated slides and de-waxed in xylene. Nonspecific background staining was reduced by microwaving the sections for two 5-min intervals in $0.05 \mathrm{M}$ Tris- $\mathrm{HCl}$ $(\mathrm{pH} 7.6)$, followed by cooling and finally rinsing in PBS. The tissue was put in retrivergen solution as per instruction manual. Primary cells were also fixed with $4 \%$ paraformaldehyde in PBS, permeabilized with $0.2 \%$ Triton X-100 in PBS. Both tissue and cells were blocked with blocking solution. Primary goat polyclonal desmin (1:200 dilution in PBS) antibody was added and incubated overnight at $4^{\circ} \mathrm{C}$. Primary antibody was removed with $6 \times$ rinses in PBS and incubated with rabbit anti-goat IgG secondary antibody conjugated to FITC for $90 \mathrm{~min}$ at room temperature in darkness. The sections were $6 \times$ rinsed in PBS and mounted in anti-fade Vectashield (Vector Laboratories) mounting medium (Cai et al. 2000). The sections and cells were visualized and photographed $(400 \times)$ with an epifluorescent microscope (Axiophot, Carl Zeiss) equipped with an FITC filter set (Zeiss \#487909) and Andor spinning disk confocal microscope.

\section{Quantitative real-time polymerase chain reaction (qRT-PCR)}

Real-time reverse transcription polymerase chain reaction was carried out as described previously (Saha et al. 2012). In brief, total RNA was extracted from uterine tissues by Trizol reagent (Invitrogen). Rat specific primers were designed and the sequences of primers used to amplify decidual 
prolactin-related protein (dPrp), Hoxa10, heparin-binding epidermal growth factor (Hbegf) and leukemia inhibitory factor receptor (Lifr) mRNAs were: dPrp: 5'-ATC CAG CGA GCT GAA GTC AT-3' (Forward), 5'- CAT GAA GTG GTG GGT TTG TG-3' (Reverse) (Matsumoto et al. 2009); Hoxa 10: 5' - AAA AGG TGG CTG TGA AAT GG-3' (Forward), 5' - TTG GGT GCA GAT CAG TGG TA-3' (Reverse); Hbegf: 5'- CTC CAG GAT TTT TGG CTG AA-3' (Forward), 5'- GAT CCC CTG TGG CTA CTT GA-3' (Reverse); Lifr: 5'- CTG GAA GCC TTT ACC CAT CA-3' (Forward), 5'- TTT GTG TTG TGG ATC GAG GA-3' (Reverse), B-Actin: 5'- GGA AAT CGT GCG TGA CAT-3' (Forward), 5'- GAA GGA AGG CTG GAA GAG AG-3' (Reverse).

Kinetic analyses were carried out for each set of primers to determine the optimum number of cycles. The number of cycles was chosen from the linear segment of the kinetic plot. The reaction was performed as follows: $95^{\circ} \mathrm{C} / 1 \mathrm{~min}, 55^{\circ} \mathrm{C} / 30 \mathrm{~s}$, $72^{\circ} \mathrm{C} / 30 \mathrm{~s}$ for $d \operatorname{Prp}(28$ cycles $) ; 95^{\circ} \mathrm{C} / 30 \mathrm{~s}, 60^{\circ} \mathrm{C} / 1 \mathrm{~min}, 72^{\circ} \mathrm{C}$ $130 \mathrm{~s}$ for Hoxa 10 (30 cycles); $95^{\circ} \mathrm{C} / 30 \mathrm{~s}, 56^{\circ} \mathrm{C} / 30 \mathrm{~s}, 72^{\circ} \mathrm{C} / 45 \mathrm{~s}$ for Hbegf ( 35 cycles); $94^{\circ} \mathrm{C} / 1 \mathrm{~min}, 54^{\circ} \mathrm{C} / 30 \mathrm{~s}, 72^{\circ} \mathrm{C} / 45 \mathrm{~s}$ for Lifr ( 30 cycles); and $94^{\circ} \mathrm{C} / 30 \mathrm{~s}, 56^{\circ} \mathrm{C} / 45 \mathrm{~s}, 72^{\circ} \mathrm{C} / 45 \mathrm{~s}$ for $B$-Actin ( 25 cycles) with a final extension at $72^{\circ} \mathrm{C}$ for an additional $10 \mathrm{~min}$. The amount of expression was measured using Applied Biosystems 7500 real-time PCR (Applied Biosystems). Summary of results derived from real-time PCR was first normalized to that of a housekeeping gene Beta-actin (Actb) and further calculated by the $2{ }^{\Delta \Delta} \mathrm{Ct}$ method and plotted as fold change. While comparing the mRNA levels between the control and study groups, the values are presented as fold changes in respect of the control mRNA levels for the D5 and D6 that were arbitrarily assigned the value 1 .

\section{Reverse transcription polymerase chain reaction (RT-PCR)}

Total RNAs were isolated from pregnant rat uterus using Trizol reagent. RNA ( $5 \mu \mathrm{g}$ ) was reverse transcribed to synthesize single-stranded cDNA using 'cDNA synthesis for PCR' kit from Fermentas (\#K1621, Maryland, USA). Amplification of the desirable genes were carried out using specific forward and reverse primers for rat chicken ovalbumin upstream promoter transcription factor ( $\mathrm{Nr} 2 \mathrm{f} 2)$, Indian hedgehog $(\mathrm{Ih} h)$, bone morphogenetic protein 2 (Bmp2), Beta-Actin (Actb) and a PCR premix solution, according to the manufacturer's instructions (PCR Reagents, Thermo Fisher Scientific). The primer sequences, Ih $h$ 5'-AAA CTC GTG CCT CTT GCC TA-3' (Forward), 5'-CAG GTG GTG ATG TTT CGA TG-3' (Reverse); Nr2f2 5'-GGA CGC ACA TAA ACC CAG TT-3' (Forward), 5'-ATT ATT TGG CTG TGG CTT GG-3' (Reverse) and Bmp2 5'-ACA AGC AGC ATC TTT TGC CT-3' (Forward), 5'-GCA AAG CAC ACC CTA CCA TT-3' (Reverse).

Following an initial heat denaturation at $95^{\circ} \mathrm{C}$ for $4 \mathrm{~min}$, the PCR cycle was repeated 35 times under the following conditions: $95^{\circ} \mathrm{C} / 30 \mathrm{~s}, 65^{\circ} \mathrm{C} / 30 \mathrm{~s}, 72^{\circ} \mathrm{C} / 45 \mathrm{~s}$ for $/ \mathrm{hh}$; $95^{\circ} \mathrm{C} / 30 \mathrm{~s}$, $65^{\circ} \mathrm{C} / 30 \mathrm{~s}, 72^{\circ} \mathrm{C} / 30 \mathrm{~s}$ for $\mathrm{Nr} 2 \mathrm{f} 2 ; 95^{\circ} \mathrm{C} / 30 \mathrm{~s}, 66^{\circ} \mathrm{C} / 30 \mathrm{~s}, 72^{\circ} \mathrm{C} / 45 \mathrm{~s}$ for Bmp2 and $94^{\circ} \mathrm{C} / 30 \mathrm{~s}, 56^{\circ} \mathrm{C} / 45 \mathrm{~s}, 72^{\circ} \mathrm{C} / 45 \mathrm{~s}$ for Actb with a final extension at $72^{\circ} \mathrm{C}$ for an additional $10 \mathrm{~min}$. The amplified PCR products were separated by $1.5 \%$ agarose gel electrophoresis and stained with ethidium bromide. The gels were viewed using Gel Doc XR+ System (Bio-Rad Laboratories) and quantified using Image J Software, version 1.45. The intensity of the PCR products was normalized by comparison with Actb and was calculated as relative amounts.

\section{Western blotting analysis}

Uterine tissues, luminal epithelial/stromal cells isolated from pregnant rat uterus and hESC were lysed in RIPA buffer (50 mmol/L Tris-Cl pH 7.4, $150 \mathrm{mmol} / \mathrm{L} \mathrm{NaCl}, 1 \% \mathrm{NP}-40$, $0.1 \%$ SDS and $0.5 \%$ sodium deoxycholate) supplemented with $1 \mathrm{mmol} / \mathrm{L}$ PMSF. Protein concentration was determined by the method of Lowry et al. (1951). About $50 \mu \mathrm{g}$ protein samples were resolved by SDS-PAGE and transferred onto a polyvinylidene difluoride membrane (Millipore) at $50 \mathrm{~V}$ for $2 \mathrm{~h}$. After blocking the non-binding sites with skimmed milk in TBST buffer $(5 \mathrm{mmol} / \mathrm{L}$ Tris- $-\mathrm{HCl}, \mathrm{pH} 7.4,136 \mathrm{mmol} / \mathrm{L}$ $\mathrm{NaCl}$, and $0.1 \%$ Tween-20) for $1 \mathrm{~h}$ at room temperature, the blots were incubated overnight at $4{ }^{\circ} \mathrm{C}$ with respective primary antibodies (dilution 1:2000) against decidualizationmediating molecules and steroid hormone receptors. The used PR antibody (PR (C-19): Sc-538; Santacruz Biotechnology) was raised against a peptide mapping at the $C$-terminus of $P R$ that detects PRA $(82 \mathrm{Kd})$ as well as PRB $(116 \mathrm{Kd})$. The blots were then washed three times with TBST buffer and incubated for $2 \mathrm{~h}$ at room temperature with HRP-linked secondary antibody at a dilution of 1:3000. The antibodies were detected with the SuperSignal West Pico Chemiluminescence Substrate (Thermo Scientific). The target bands were quantified using Image J software, version 1.45. Comparison with ACTB normalized the intensity of a specific protein band, and the results have been calculated and expressed as relative amounts.

\section{Gelatin zymography}

Pregnant rat uterine tissue was suspended in PBS containing protease inhibitors, centrifuged at $13,680 \mathrm{~g}$ and the supernatant was collected as a PBS extract. The remaining pellet was extracted in the lysis buffer $(10 \mathrm{mM}$ Tris- $\mathrm{HCl} \mathrm{pH}$ $8.0,150 \mathrm{mM} \mathrm{NaCl}, 1 \%$ Triton $\mathrm{X}-100$ plus protease inhibitors) and centrifuged at $13,680 \mathrm{~g}$ for $15 \mathrm{~min}$ to obtain Tx extract. For the assay of MMP9 and MMP2 activity, PBS and Tx extracts were subjected to SDS-polyacrylamide gel electrophoresis with a $8 \%(\mathrm{w} / \mathrm{v})$ acrylamide gel containing gelatin $(1 \mathrm{mg} / \mathrm{ml})$ under non-reducing conditions. The gels were washed with $2.5 \%$ Triton X-100 to remove the SDS and then incubated at $37^{\circ} \mathrm{C}$ for $18 \mathrm{~h}$ in calcium assay buffer $(40 \mathrm{mM}$ Tris- $\mathrm{HCl}(\mathrm{pH}$ 7.4), $10 \mathrm{mM} \mathrm{CaCl}_{2}, 0.2 \% \mathrm{NaCl}$ ) (Swarnakar et al. 2005). After that, the gel was stained with Coomassie brilliant blue R-250, and gelatinolytic activity was detected as unstained bands on a blue background. Densitometric analysis of zymograms by using the free available Image J software program was used for the quantitative measurement of MMPs. Data were obtained as arbitrary units, and MMP production levels in the treatment groups were compared with the control.

\section{Chemotactic migration assay}

Directed migration was monitored by transwell migration assay using non-coated cell culture inserts with $8 \mathrm{mM}$ pores 
for 24-well recipient plates (BD Biosciences, NJ, USA). Treated hESC were plated at a density of $3 \times 10^{4}$ cells/insert in $300 \mu \mathrm{L}$ DMEM without serum. The lower reservoir received $750 \mu \mathrm{L}$ DMEM with serum. Each treatment was performed in quadruplicate wells. Migration was allowed to proceed for $18 \mathrm{~h}$. After the incubation, cells were fixed in $3.7 \%$ formaldehyde for $2 \mathrm{~min}$ and permeabilized in methanol for $20 \mathrm{~min}$. Cell culture inserts were then washed with PBS and cells stained with Giemsa stain for $15 \mathrm{~min}$. After staining, the non-migrated cells on the upper surface of the filter were removed by scraping. The cells that had migrated to the lower side of the filter were counted in 10 unit field per filter at $20 \times 1.6 \times$ magnification using a Zeiss microscope.

\section{Statistical analysis}

Data were expressed as mean \pm S.E.M. The results were analysed by $t$-test and one-way ANOVA, followed by Newman-Keuls test as applicable, using the GraphPad Prism 3.0 software (GraphPad Software). A $P$ value $<0.05$ was considered to be statistically significant.

\section{Results}

\section{Percentage yield, encapsulation efficiency and drug loading}

The method employed resulted in self-assembly of PLGA into PN-containing puerarin. The percentage yield, encapsulation efficiency and drug loading were $68.29 \pm 6.62,51.33 \pm 10.32$, and $12.76 \pm 3.00 \%$, respectively (Table 1 ).

\section{Surface morphology of PN}

The surface morphology of the $\mathrm{PN}$ was determined by TEM and AFM. The TEM picture (Fig. 1B) shows spherical $\mathrm{PN}$ with smooth surfaces. The AFM picture also shows smooth surfaces of the PN without any cracks or pinholes (Fig. $1 \mathrm{~A}_{1}$ and $\mathrm{A}_{2}$ ).

\section{Particle size and surface charge}

The size of the PN is reported to influence the cellular entry. Larger particles are taken up by the cell via the lymphatics, while the smaller particles are taken up by endocytosis (Savic et al. 2003). The DLS picture shows the size distribution of PN (Fig 1C). The mean

Table 1 Physicochemical properties of the nano-puerarin.

\begin{tabular}{ll}
\hline Physiochemical properites & Mean \pm S.E.M. \\
\hline Encapsulation efficiency (\%) & $51.33 \pm 10.32$ \\
Yield (\%) & $68.29 \pm 6.62$ \\
Drug loading (\%) & $12.76 \pm 3.00$ \\
Particle size (nm) & $147.3 \pm 29.69$ \\
Poly dispersity index (PDI) & $0.259 \pm 0.03$ \\
Zeta-potential (mV) & $39.95 \pm 23.36$ \\
\hline
\end{tabular}

Data are presented as mean \pm S.E.M. $(n=3)$. particle diameter and polydispersity index were $147.30 \pm 29.69 \mathrm{~nm}$ and $0.259 \pm 0.030$ respectively. Particle aggregation and cellular adhesion of the PN depend on the electrical charge on their surface. The zeta-potential of the $\mathrm{PN}$, as determined by dynamic light scattering, was $39.95 \pm 23.36 \mathrm{mV}$ (Table 1).

\section{In vitro release kinetics and cellular uptake of PN}

After an initial burst release, a slow release of puerarin from the $\mathrm{PN}$ was observed, and the percentage of release was $95 \%$ in 7 days. This observation shows that envelopment of puerarin in the $\mathrm{PN}$ resulted in a sustained release of the drug (Fig. $2 \mathrm{~A}$ ). Endometrial stromal cell uptake of PLGA nanoparticles, as evidenced by red fluorescence, was detectable at $30 \mathrm{~min}$ of exposure to Nile red-stained nanoparticles. The red fluorescence increased to maximum level after 2 h (Fig. 2B).

\section{Evaluation of anti-implantation effect \\ Optimization of dose and duration of treatment}

The administration of $\mathrm{PN}$ to rats from D1 to D4 resulted in a dose-dependent antifertility effect (Fig. 3A). The rate of pregnancy failure gradually increased with an increase in the dose of PN (Fig. 3B, C, D, E, and F). A complete absence of the implantation sites was observed at the dose level of $35 \mathrm{mg} / \mathrm{kg} /$ day (Fig. 3F). When treated during D1-3 and D1-2, MED 100 for termination of pregnancy was $50 \mathrm{mg} / \mathrm{kg} /$ day and $75 \mathrm{mg} / \mathrm{kg} /$ day, respectively. This study suggests that PN is effective at $\sim 1 / 4$ th dose of the parent molecule. All subsequent studies were performed with $75 \mathrm{mg} / \mathrm{kg} /$ day administered on D1 and D2.
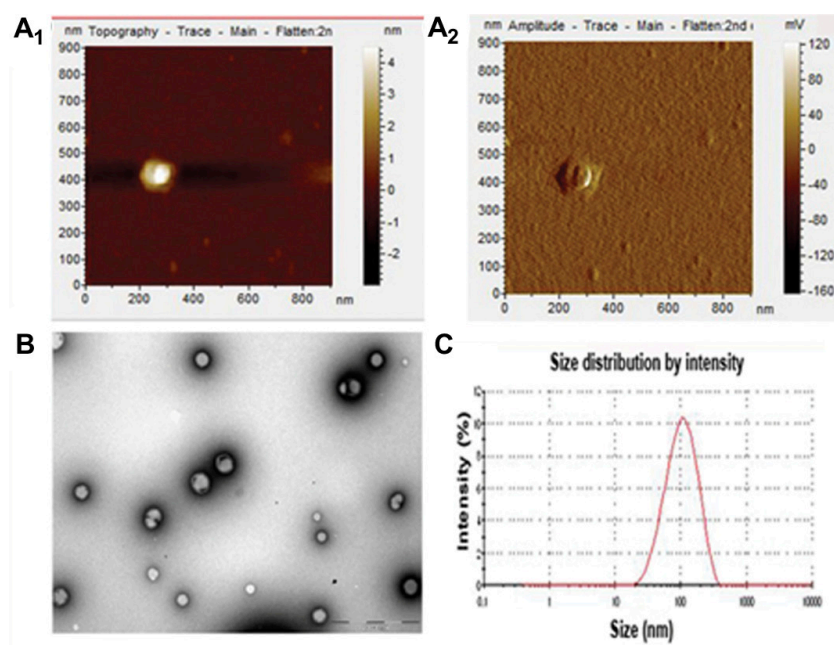

Figure 1 Surface morphology and distribution of PN. The AFM $\left(A_{1}, A_{2}\right)$ and TEM (B) panels depict the smooth surface and spherical nature of the PN. The DLS graph $(C)$ represents the size and mono-dispersive nature of $\mathrm{PN}$. 


\section{Evaluation of decidualization in vitro and in vivo}

The effect of PN on decidualization was examined by weight of the traumatized uterine horns and expression of various specific decidual markers including ALP,

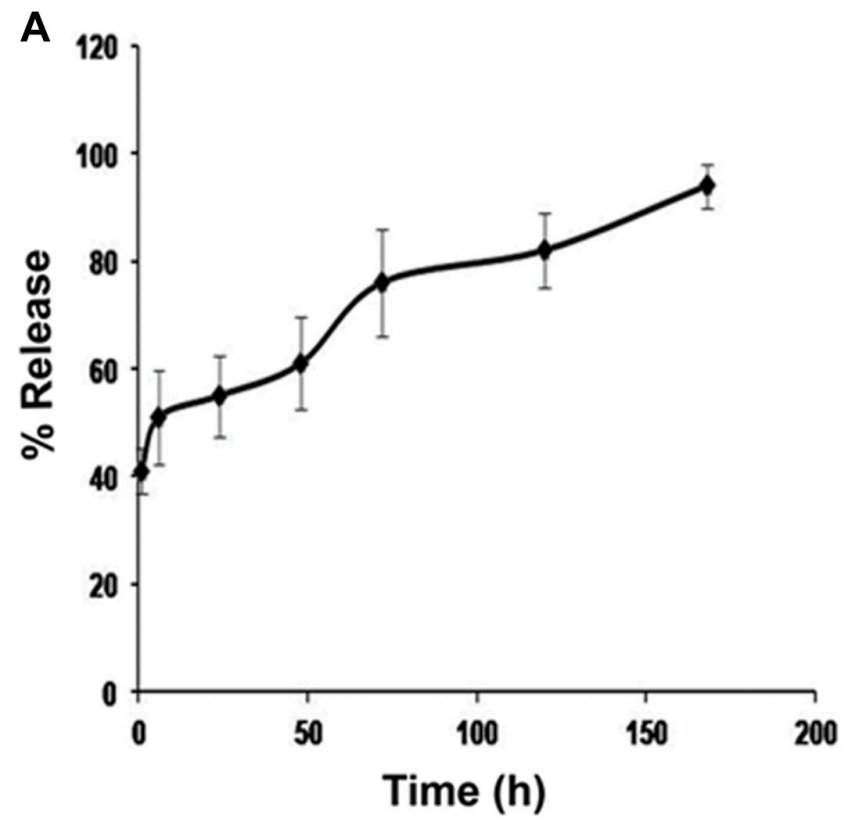

B

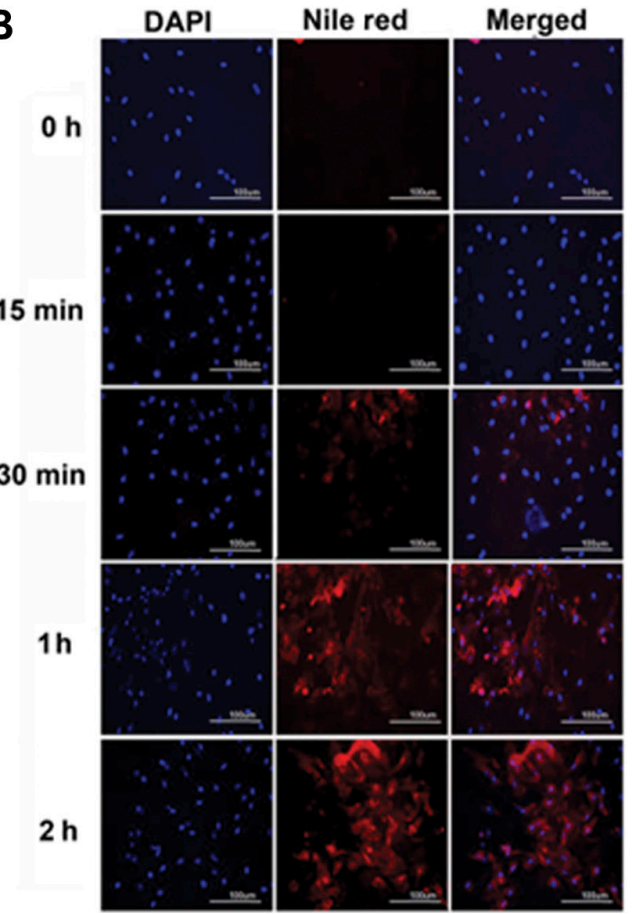

Figure 2 In vitro release of puerarin from $\mathrm{PN}$, and stromal cell uptake of $\mathrm{PN}$. In vitro release kinetics shows a sustained release of puerarin from the PN over a 7-day period (A). Data are expressed as mean \pm S.E.M. $(n=3)$. (B) The uptake of Nile red-stained PLGA by endometrial stromal cells. Endometrial stromal cells were incubated with Nile red-stained PLGA nanoparticles. Fluorescence microscopy (200x) detected the presence of red fluorescence of Nile red within the cells at different time points. Nuclei were stained with DAPI. desmin, dPrp, and IGFBP1. In the control PS rats, the weight of the oil-infused traumatized uterine horns on D8 significantly increased over that of the corresponding non-tramatized horns. By contrast, the PN-treated rats exhibited no increase in the uterine horn weights (Fig. 4A) following oil infusion. In the control PS rats, the ALP activity (i.e. activity $\times 10^{-3} \mathrm{U} / \mathrm{mL}$ ) in the untreated contra-lateral horns remained statistically comparable between D5 and D6. The oil-infused horn, however,
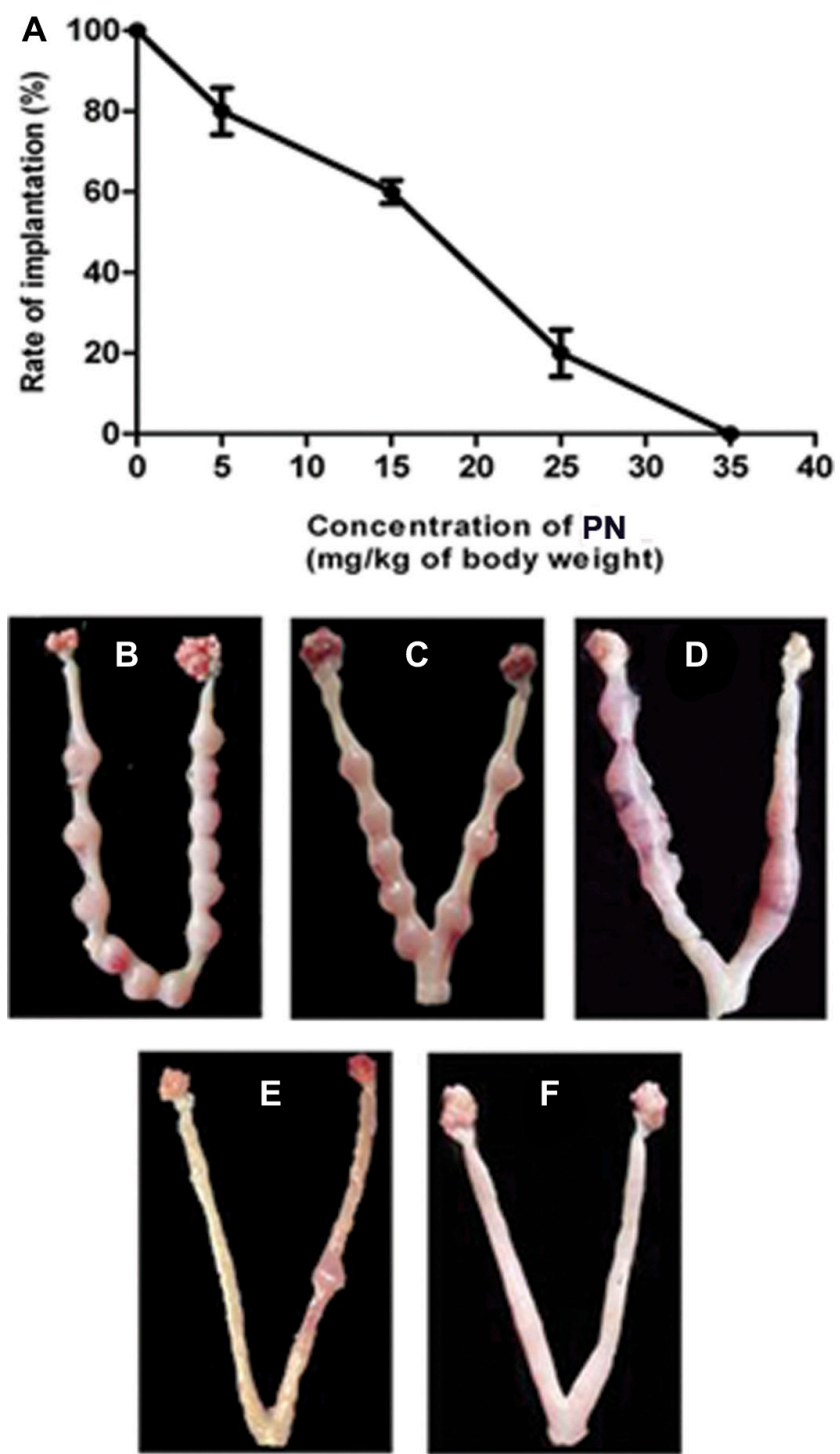

Figure 3 Anti-implantation effect of PN. Pregnant rats were orally administered with the void polymer (control) or PN at different dose levels for D1-D4 of pregnancy and laparotomized on D9 when the uteri were examined for the presence/absence of the embryo.

Dose-response curve (Fig. 3A) shows a dose-dependent inhibition of embryo implantation, and the $\mathrm{MED}_{100}$ of $\mathrm{PN}$ is $35 \mathrm{mg} / \mathrm{kg}$ per day for D1-D4 of pregnancy. Each datum point on X-axis represents the mean \pm S.E.M. of implantation rate (\%) of four to six rats. (B-F) The photographs of implantation swellings on D9 in rats treated with the void polymer (B) or PN at $5 \mathrm{mg}(\mathrm{C}), 15 \mathrm{mg}(\mathrm{D}), 25 \mathrm{mg}(\mathrm{E})$, and $35 \mathrm{mg} / \mathrm{kg}$ (F) per day dose levels. 
exhibited significantly increased ALP activity on D6 over that of D5, and on both days the enzyme activity was higher as compared to that of the corresponding untreated contra-lateral horn. In the PN-treated rats, the ALP activity in the traumatized and untreated horns on D5 and D6 remained statistically indifferent, which were almost comparable to that of the non-traumatized horn of the untreated control rats (Fig. 4 $\mathrm{B}_{1}$ ). Hormoneinduced decidualization of stromal cells in culture demonstrated the same response. The increased stromal cell ALP activity following hormone stimulation was dose-dependently inhibited by PN (Fig. 4 $\mathrm{B}_{2}$ ). Immunofluorescence and western blotting analysis of desmin in the decidualized PS rat uteri on D5 and D6 (Fig. $4 \mathrm{C}_{1}$ and $4 \mathrm{E}$ ) or hormone-stimulated stromal cells (Fig. $4 C_{2}$ ) demonstrated attenuated desmin expression under the influence of PN. PN also attenuated the expression of $d$ Prp and IGFBP1, the two recognized markers of decidualization, in the decidua-induced PS uterine horns. In the control group, expression of $d$ Prp (Fig. 4D) and IGFBP1 (Fig. 4E) increased between D5 and D6, whereas the PN-treated rat uteri demonstrated decrease in the expression.

\section{Uterine expression of Hoxa10, Hbegf, Lifr, CCND3 and CDK4}

To further investigate the $\mathrm{PN}$-induced inhibition of decidualization, we analysed the expression of CYCLIN D3 and CDK4 (Fig. 5A) at protein levels. Expression of these proteins is down-regulated on D5 and D6 of pregnancy in the PN-treated group as compared with the controls. Change in the expression of these cell cycle regulatory molecules prompted us to examine the effect of $\mathrm{PN}$ on their upstream regulators. The qRT-PCR data on the uterine expression
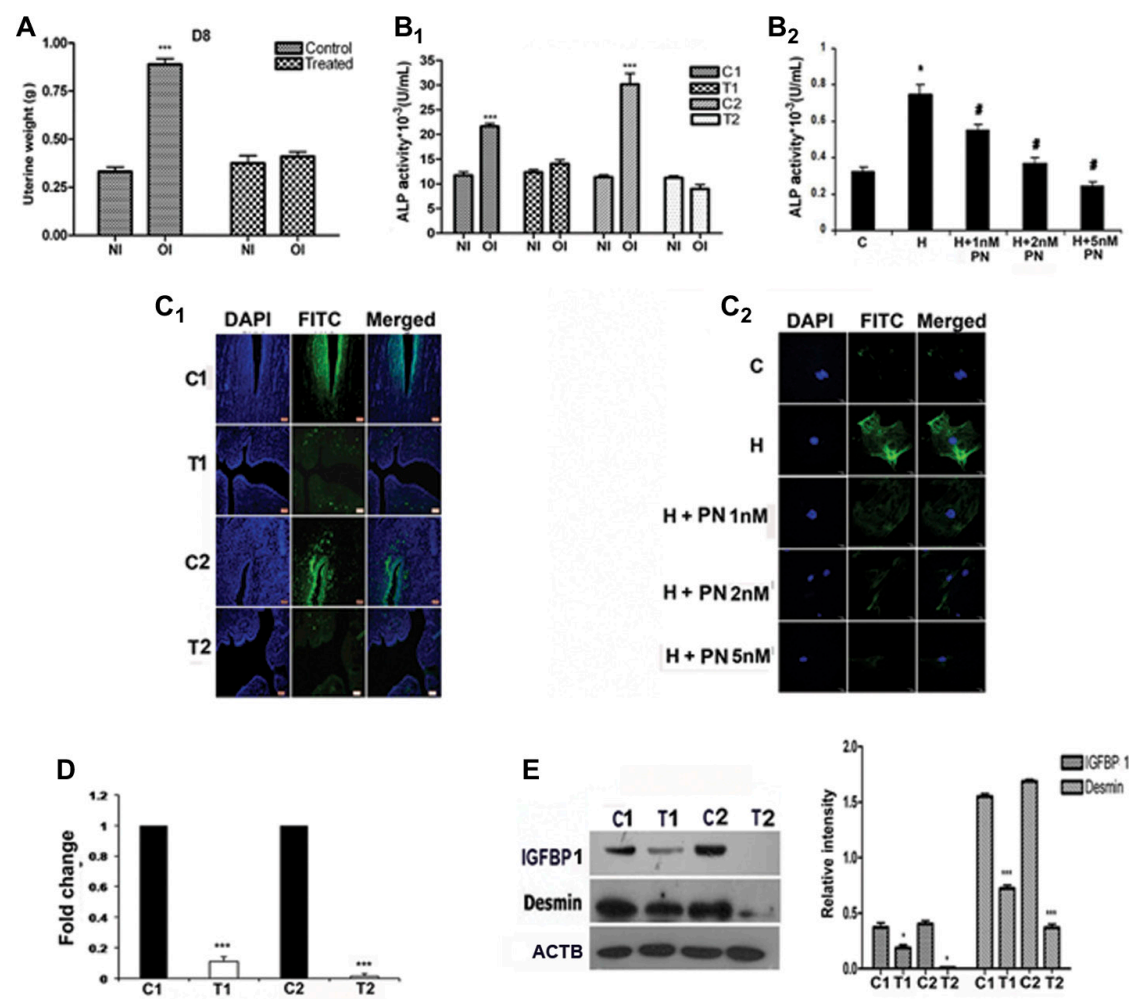

Figure 4 In vivo and ex vivo effect of PN on artificially-induced decidualization. (A) A significant increase in weight of the oil-infused uterine horn of the control rats denoting decidualization. The PN-treated rats exhibit no statistical increase in the weight of the oil-infused horns that mark inhibited decidualization. PN treatment also inhibits the uterine $\left(B_{1}\right)$ and cultured rESC $\left(B_{2}\right)$ ALP activity. (C) The overlaid

immunofluorescence images of PS rat uterine sections $\left(C_{1}\right)$ and cultured stromal cells $\left(C_{2}\right)$ analysed for the expression of desmin. Yellowish green deposits indicate the sites of positive staining. As compared with void polymer-treated group, PN treatment markedly reduces the expression of endometrial desmin on D5 and D6 $\left(C_{1}\right)$, and dose-dependently inhibits the hormone-induced expression of desmin in the cultured stromal cell $\left(C_{2}\right)$. (D) The mRNA expression level of endometrial dPrp in PS rats as evaluated by qRT-PCR. Relative to the day-wise corresponding controls, PN reduces $d$ Prp expression levels to $\sim 10 \%$ on D5 and to $\sim 1 \%$ on D6. (E) The western blot data on the expression of uterine desmin and IGFBP1 in PS rats. Both on D5 and D6, the expression levels of IGFBP1 and desmin are significantly lower in the PN-treated group as compared with the corresponding controls. The details of the treatment and protocol are described in the 'Materials and methods' section. Each immunofluorescence image is one representative of four to five replicates of the concerned group (400x). The experiments were repeated three times with similar results and data were analysed by $t$-test and ANOVA. Figure bars with asterisk vary significantly $\left({ }^{*} P<0.05,{ }^{* * *} P<0.001\right)$, ${ }^{\sharp} P<0.05$ (H vs PN treatment). PS, pseudopregnancy; D, day of pseudopregnancy. NI, non-infused uterine horn; OI, oil-infused uterine horn; $\mathrm{C}$, untreated control; $\mathrm{H}$, hormone-primed control; $\mathrm{C} 1, \mathrm{C} 2$, control PS rats on D5 and D6, respectively; $\mathrm{T} 1, \mathrm{~T} 2, \mathrm{PN}$-treated PS rats on D5 and D6 respectively. 
of candidate mRNAs in the control and treated groups on D5 and D6 are shown in Fig. 5B. With respect to the corresponding day control, the expression of Hbegf, Hoxa10 and Lifr mRNAs in the PN-treated group was remarkably reduced.

\section{Uterine expression of $\mathrm{Nr} 2 \mathrm{f} 2, \mathrm{Bmp} 2$ and its regulators}

The RT-PCR data on the uterine expression of candidate mRNAs in the control and treated groups on D5 pregnant rat are presented in Fig. 6. There was a reduction in the expression of $\mathrm{Nr} 2 \mathrm{f} 2, \mathrm{Bmp} 2$ and $/ h h$ mRNAs in the treated group as compared with control group.

\section{ERK and stromal cell migration}

To further evaluate the possible mechanism of action of $\mathrm{PN}$, we checked the expression of ERK $1 / 2$ and $p E R K^{1} 1 / 2$ in D5 and D6 pregnant rat uteri (Fig. 7A). The control pregnant rats showed up-regulation of the expression of $\mathrm{pERK} 1 / 2$ from D5 to D6. PN treatment significantly inhibited the activation of ERK $1 / 2$ as marked by an increased $E R K^{1} 1 / 2$ and decreased $p E R K 1 \frac{1}{2}$ expression on D6 as compared with D5. In transwell migration assay (Fig. 7B), hESC exhibited the chemotactic response to hormone (MPA, $E_{2}$, and db-cAMP) by a significant increase in the migration of the decidualizing cells. Pre-exposure to PN dose-dependently inhibited the hormone-induced hESC migration. Gelatin zymography of MMPs demonstrated that pro- and active MMP2 did not differ between the groups treated with or without $\mathrm{PN}$; however, PN remarkably inhibited the expression of pro-MMP9 activity. In the control group, the pro-MMP9 expression on D6 increased by $\sim 7$-fold as compared with that of D5. The treated rats, by contrast, exhibited little or no change in pro-MMP activity between the D5 and D6, when the expression levels were comparable to that of control D5 pregnant rat (Fig. 7C). In cultured hESC, PN dose-dependently down-regulated the hormone-induced activation of ERK and MLC and up-regulated the expression of RHOA, ROCK, and pMLC (Fig. 7D).

\section{Uterine expression of ESR1, ESR2, and PGR}

Endometrial compartment-wise expression of ESR and PGR was evaluated at the protein level. Western blotting analysis (Fig. 8) showed that the two compartments discrepantly expressed the two ESR subtypes. The epithelial expression of ESR1 in the treated group significantly increased over that of the controls, but the stromal cell expression remained comparable to that of controls. By contrast, the epithelial cell expression of ESR2 did not differ between the groups, but the stromal cells exhibited increased expression of ESR2. There was a very faint expression of PR-B in both the compartments of the control and treated groups.
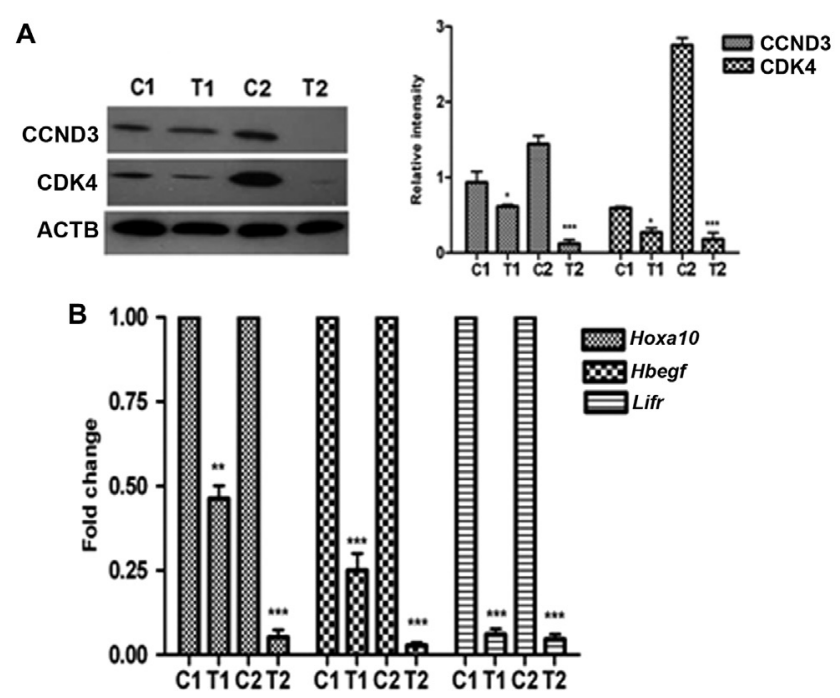

Figure 5 Effect of PN on the expression of decidualization-mediating cell cycle regulating molecules and their upstream regulators. Uterine expression of CCND3 and CDK4 was analysed by western blotting (A). The figure shows an increase in CCND3 and CDK4 expression on D6 over that of D5 in the control rats, while the expression levels in the $\mathrm{PN}$-treated group are significantly lower on both days as compared with the corresponding day control. (B) The qRT-PCR data on the Hoxa10, Hbegf, and Lifr mRNAs. Relative to the day-specific corresponding controls, the PN-treated group shows significantly reduced expression of all the three mRNAs. The data shown are the means \pm S.E.M. of three individual experiments analysed by ANOVA. Figure bars with asterisk vary significantly $\left({ }^{*} P<0.05,{ }^{* *} P<0.01,{ }^{* * *} P<0.001\right) . \mathrm{C} 1, \mathrm{C} 2$ : control pregnant rats on D5 and D6, respectively; T1, T2: PN-treated pregnant rats on D5 and D6, respectively.

The PR-A expression, however, was down-regulated in the epithelial as well as stromal compartments of the treated rat uteri.
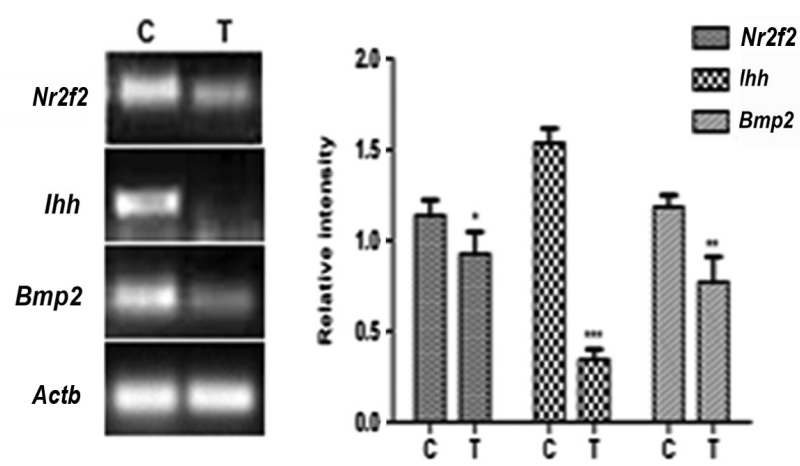

Figure 6 Effect of PN on mRNA expression levels of Nr2f2, Bmp2 and $I h h$ in pregnant rat uterus on D5. The figure represents the RT-PCR data on the relative mRNA levels normalized to that of Actb. The bands and their densitometric analysis show that PN significantly attenuates the expression of $\mathrm{Nr} 2 \mathrm{f} 2, \mathrm{Ih} h$, and Bmp2, as compared with those of the control group. Values represent the mean \pm S.E.M. of three individual experiments analysed by ANOVA. Figure bars with asterisks vary significantly $\left({ }^{*} P<0.05, * * P<0.01\right.$,

$\left.{ }^{* * *} P<0.001\right)$. C, void polymer-treated control; T, PN-treated. 

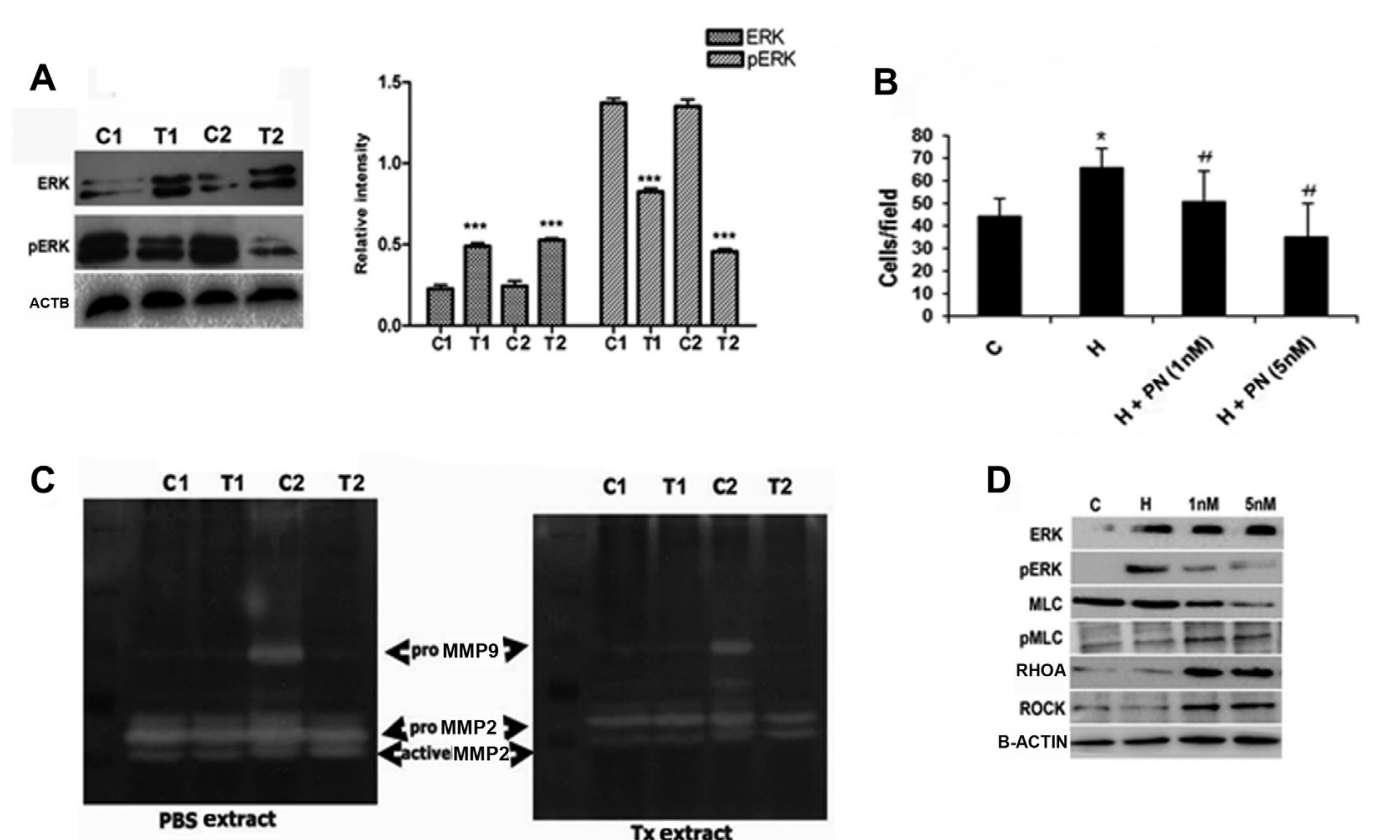

$\begin{array}{llll}\text { C1 } & \text { T1 } & \text { C2 } & \text { T2 }\end{array}$
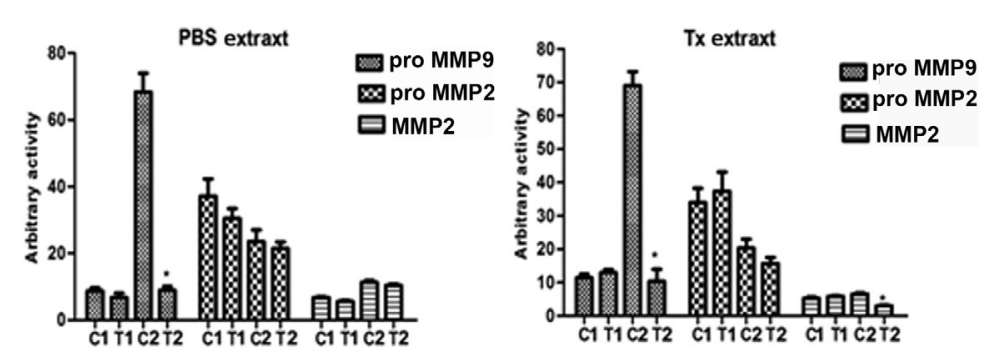

D
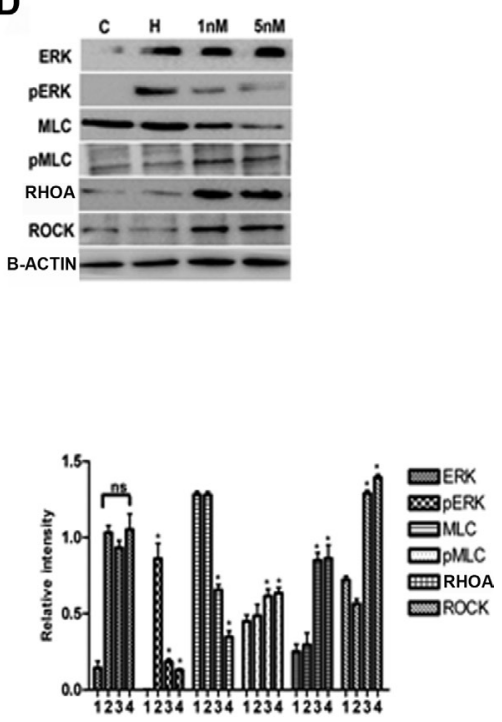

Figure 7 Effect of PN on stromal cell migration and related signalling molecules. Western blotting analysis data (A) exhibit increased expression of ERK $1 / 2$ and attenuated expression of $p E R K 1 / 2$ in the PN-treated group on D5 and D6, as compared with the corresponding control pregnant rat uteri. (B) Transwell migration of hESC. The histogram reflects a dose-dependent inhibition of hormone (MPA, $E_{2}$ and db-cAMP)-induced hESC migration by PN. Gelatin zymograms (Fig. 7C) show that PN significantly attenuates the endometrial expression of pro-MMP9 on D6 of pregnancy. (D) Western analysis data on the stromal cell migration-regulating molecules in hormone-stimulated cultured hESC pretreated with/ without PN. PN dose-dependently inhibits the hormone-induced expression of $\mathrm{pERK} 1 \frac{1}{2}$ and $\mathrm{MLC}$ and up-regulates the expression of $\mathrm{pMLC}$, RHOA and ROCK. The details of the treatment and protocol are described in the 'Materials and methods' section. Values represent the means \pm S.E.M. of three individual experiments. Data were analysed by ANOVA. ${ }^{*} P<0.05$; ${ }^{* * *} P<0.001$; and ${ }^{*} P<0.05$ (PN-treated group vs hormone-primed group). C1, C2: control pregnant rats on D5 and D6 respectively; T1, T2: PN-treated pregnant rats on D5 and D6 respectively. The numerical in the $\mathrm{X}$-axis of the graphs represent: 1: untreated control, 2: hormone-primed control, 3: pre-treated with $1 \mathrm{nM}$ PN, and 4: pretreated with $5 \mathrm{nM}$ PN.

\section{Discussion}

With a long-term objective to develop a non-steroidal EC formulation, we had earlier investigated the antiimplantation potential of puerarin. Administration of puerarin at $300 \mathrm{mg} / \mathrm{kg}$ for D1-2 or $125 \mathrm{mg} / \mathrm{kg}$ for D1-4 completely disrupted the establishment of pregnancy in rats (Saha et al. 2012). Puerarin exerted no significant toxic effects at a dose level up to $250 \mathrm{mg} / \mathrm{kg} /$ day administered consecutively for 28 days (Chung et al. 2009). The high dose of puerarin, therefore, should not be a major constraint in exploring its future potential as an antifertility agent. However, NP holds tremendous potential as an efficient drug delivery system (Suri et al. 2007). PN is reported to have excellent stability, enhanced intestinal absorption and increased bioavailability after oral administration (Liu et al. 2009, Wu et al. 2009). In this study, we developed PLGA-encapsulated PN, studied its anti-implantation effect and mapped the molecular pathway underlying its action. We report that $\mathrm{PN}$ attenuates the decidualization process and prevents the establishment of pregnancy at significantly reduced dose levels compared with puerarin.

The size, surface charge and dispersity of NP are of utmost importance related to their cellular entry and maintaining stability in the dispersion. As evaluated by a battery of tests, smooth-surfaced and spherical PLGAencapsulated PNs having a mean diameter of $\sim 147 \mathrm{~nm}$ were obtained with good yield, efficient encapsulation, high drug loading and high degrees of stability. In vitro 

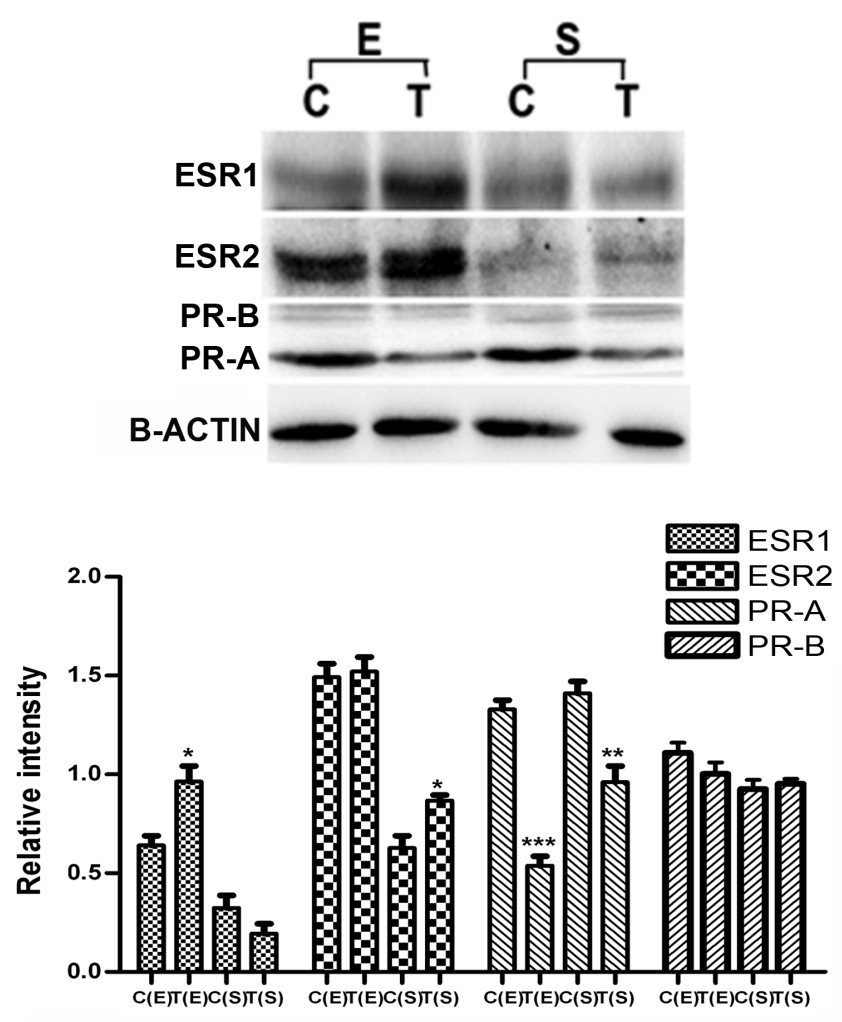

Figure 8 Effect of PN on the uterine expression of ESR and PGR. Western blot analysis demonstrates increased epithelial expression of ESR1 and stromal expression of ESR2 in the PN-treated D5 pregnant rat uterus. Attenuated PR-A expression is observed both in the epithelia as well as stroma. Values represent the means \pm S.E.M. of three individual experiments. Figure bars with asterisks vary significantly $\left({ }^{*} P<0.05,{ }^{* *} P<0.01,{ }^{* * *} P<0.001\right)$. C (E), control rat luminal epithelia; $\mathrm{T}(\mathrm{E}), \mathrm{PN}$-treated rat luminal epithelia; $\mathrm{C}(\mathrm{S})$, control rat stromal cells; $\mathrm{T}(\mathrm{S}), \mathrm{PN}$-treated rat stromal cell.

assessment demonstrated that PN slowly and steadily released puerarin, which was readily taken up by the cultured decidual cells.

The antifertility study shows that oral doses of $\mathrm{PN}$ at $35 \mathrm{mg} / \mathrm{kg}$ for D1-D4 or $75 \mathrm{mg} / \mathrm{kg}$ for D1-D2 are the minimum effective regimen that completely disrupts pregnancy. The effective doses of PN are $\sim 1 / 4$ th of that of puerarin, as reported earlier (Saha et al. 2012). Since PN was loaded with $\sim 13 \%(\mathrm{w} / \mathrm{w})$ of puerarin (Table 1$)$, the effective dose of puerarin is calculated to be $\sim 9.75 \mathrm{mg} / \mathrm{kg}$.

Decidualization of uterine stromal cells is a critical prerequisite for successful implantation. PN disrupted the decidualization process. The endometrium represents the glandular compartment of the uterus consisting of the central luminal epithelium surrounded by stroma containing uterine glands (Wetendorf \& DeMayo 2012). The endometrium receives the fertilized egg from the oviduct and provides the requisite environment for implantation of the embryo and subsequent placentation. In the murine uterus, implantation occurs 5 days after fertile mating, during a period known as the 'window of receptivity'. During this time, the blastocyst has a limited time frame to get implanted into the uterine lumen (Wang \& Dey 2006). Our earlier report postulated that puerarin disrupts the endometrial receptivity and prevents implantation (Saha et al. 2012). In the rats, the uterus responds to an implanting blastocyst by transforming the endometrium into decidua (Wooding \& Flint 1994), a process involving proliferation and transformation of endometrial stromal fibroblasts to polygonal epithelial-like decidual cells (Ramathal et al. 2010). Thus, implantation necessarily requires endometrial decidualization to occur, while induction of decidualization primarily needs the mechanical trauma, which in pregnancy is exerted by the active blastocyst. Therefore, $\mathrm{PN}$-mediated prevention of endometrial receptivity may be an anti-decidualizing effect exerted directly on the endometrium; alternatively, PN may exercise a direct blastotoxic effect, and the antidecidualizing effect is a secondary consequence of the absence of active blastocyst. To identify the specific target of puerarin effect, we adopted a PS rat model.

In rats, $\mathrm{CL}$ of estrus cycles is an ephemerally active structure that secretes sufficient progesterone $\left(\mathrm{P}_{4}\right)$ only for a brief period shortly after ovulation (Keyes \& Wiltbank 1988). However, in pregnancy the coital act, or in PS the artificial cervical stimulus mimicking the coital act, stimulates the release of sufficient quantity of pituitary prolactin that rescues the $\mathrm{CL}$ and allows them to persist until D11/12 when in pregnancy the placenta takes over (Terkel 1988). In the mouse and rat, the maintenance of $C L$ production and peripheral level of $\mathrm{P}_{4}$ until the establishment of placental physiology is independent of the presence of embryo (McCracken et al. 1999). Therefore, in pregnancy and PS the uterus is exposed to an identical hormonal environment until D11/12. Under such an hormonally conditioned state, the D4 uterus of PS rat, like that of pregnant rats, is receptive, when artificial stimuli (e.g. intrauterine oil infusion) can trigger decidualization. The deciduoma, as it is known, appears very similar to the decidua of normal pregnancy (Parr \& Parr 1989). Thus, PS stands as a reliable tool to discriminate between the effects exerted directly on the endometrium or mediated via the embryo. The present observation that PN treatment effectively blocked the oil-induced decidualization in the PS rats clearly proves that the anti-decidualizing effect of PN is a direct one; however, an additional effect of $\mathrm{PN}$ on the embryo, if any, is not ruled out.

Many genes are up- or down-regulated in the ESC undergoing decidualization. A unique set of proteins and peptides is secreted. The fibroblasts acquire large amounts of desmin intermediate filaments. There occurs an increase in the activity of endometrial stromal cell alkaline phosphatase, and IGFBP1 and dPRL are preferentially expressed (Glasser \& Julian 1986, Yee \& Kennedy 1988, Gu et al. 1994, Tamura et al. 2012). These correlate with decidualization and, therefore, serve as markers of decidualization. That PN attenuates the decidualization 


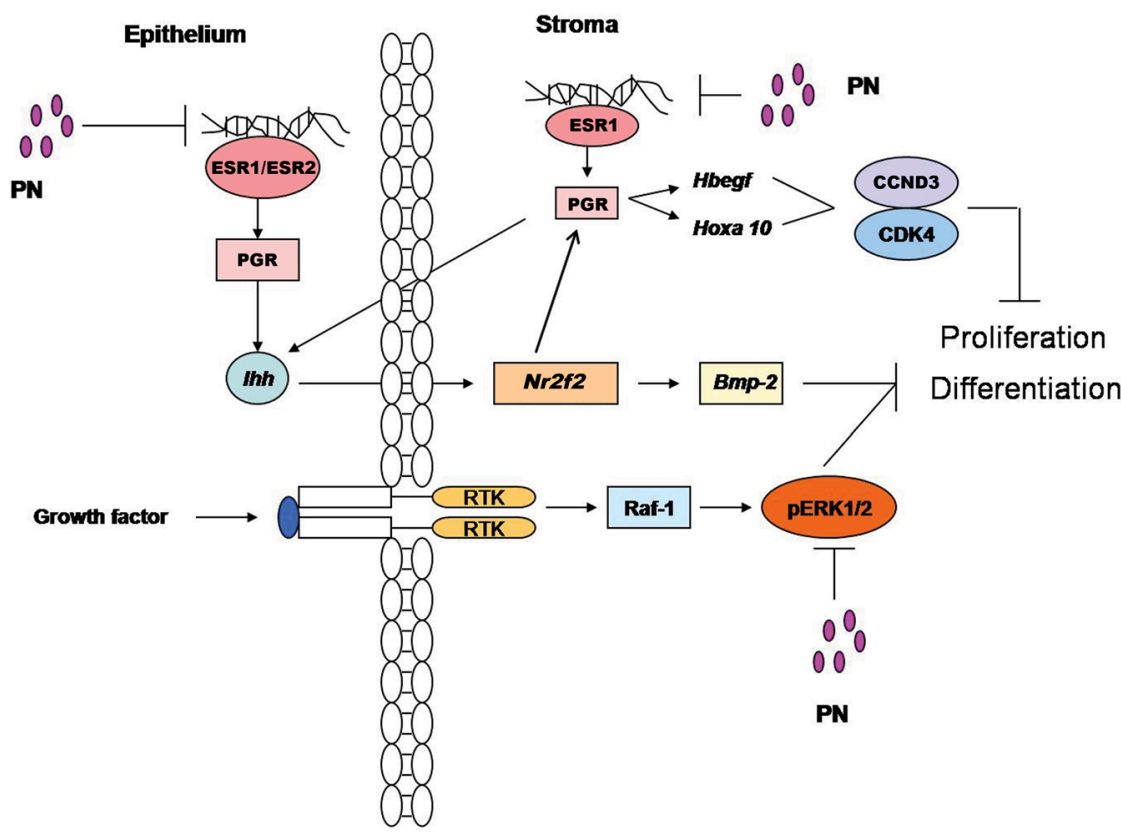

Figure 9 Working model of $\mathrm{PN}$ in mediating anti-decidualizing effect. PN alters the epithelial and stromal cell expression of ESR subtypes to attenuate endometrial PGR expression. Withdrawal of PGR activity, in turn, withholds the $\mathrm{P}_{4}$-mediated Ihh-Nr2f2-Bmp2 signalling and thereby provokes continued epithelial proliferation to block embryo attachment at one end, and suppresses the Bmp2 regulated stromal cell differentiation on the other. PN may additionally inhibit the growth factor-mediated activation of the MAPK pathway that promotes stromal cell proliferation and differentiation. process was straightforward by no increase in weight of the traumatized horn and attenuated the uterine/rESC expression of desmin, ALP, IGFBP1, and dPrp.

Differentiation of stromal cells into decidual cells involves changes in endometrial cytoskeletal architecture. The cytoskeletal organization is determined primarily by actin-myosin II interactions. The phosphorylation of MLC20 governs the process (de Lanerolle \& Paul 1991, Tan et al. 1992) under the regulation of MLC kinase. Early in the decidualization process, marked changes occur in the cell adhesion properties and extracellular matrix, and the cytoskeletal structure is destabilized due to a significant decline in MLC kinase activity accompanied by a decrease in MLC20 phosphorylation. Formation, interaction, and activation of the components of myosin II and filamentous actin are also controlled by RHOA that acts via its effector protein kinase, ROCK1 (Riento \& Ridley 2003, Jaffe \& Hall 2005). Reports suggest that RHOA activity in hESC is anti-migratory; it induces ROCK activity leading to increased level of phosphorylated MLC (Weimar et al. 2013). We demonstrated that in cultured ESC, PN dose-dependently increased MLC20 phosphorylation and up-regulated the expression of RHOA and ROCK that perhaps promoted actin-myosin interaction and obstructed the destabilization process.

Decidualization is a tightly controlled event that involves a balance between the expression of cyclins, CDKs, and CDKIs (Das 2009). Based on the findings of multiple approaches, it is suggested that CCND3, a G1-phase cell cycle regulator, is closely associated with stromal cell proliferation, differentiation, and polyploidy events during decidualization (Das 2009). CCND3 and its associated kinase, CDK4, are remarkably expressed during the onset and progression of implantation (Das 2009). In vitro and in vivo studies have substantiated that
Hoxa 10 and Hbegf are perhaps the upstream regulators of these uterine cell cycle regulatory signalling pathways (Das 2009). These two pathways converge to a downstream cell cycle regulatory circuitry consisting of CCND3 and CDK4 to appropriately balance proliferation and differentiation for the full spectrum of decidualization (Das 2009). Another crucial factor involved in implantation is the LIF that plays dual roles: a critical role in uterine bed preparation initially and in attachment reaction later (Dey et al. 2004). LIF binds to Lifr and shares gp 130 as a common signal transduction partner with other cytokines (Mathieu et al. 2012). Uterine expression of LIF and its receptors coincide with blastocyst implantation. LIF acts on the uterine epithelium in an autocrine/paracrine manner, and in vitro LIF stimulates proliferation of stromal fibroblasts (Salamonsen et al. 1997). The uterine effect of LIF seems to be mediated via Hbegf since Lif-/- mice show deficient expression of Hbegf (Song et al. 2000). Thus, the cell cycle regulatory signalling pathways involved in decidualization are under the commands of Hbegf, Hoxa 10 and Lifr. By using in vivo treatment model, we indeed demonstrate that PN enforces inhibition of Hbegf, Hoxa 10 and Lifr and their effector molecules, CCND3/CDK4.

Implantation is the result of reciprocal interaction between the implantation-competent blastocyst and receptive uterus (Hamatani et al. 2004). The endometrium differentiates into an altered state when the blastocysts are capable of mediating effective two-way communication to initiate the process of implantation (Dey et al. 2004). The molecular mechanism underlying this interaction is poorly defined; however, a novel signalling pathway involving Ihh-Nr2f2-Bmp2 has been implicated in the process (Kurihara et al. 2007). The Pgr-knockout mouse model demonstrated that 
early pregnancy is dependent on the functional PGR signalling within the uterine compartments. Ihh has been identified as an acute PGR target gene (Kurihara et al. 2007). It transduces its signal via the expression of stromal $\mathrm{Nr} 2 \mathrm{f} 2$ that in turn regulates decidualization through its major downstream effector, Bmp2 (Kurihara et al. 2007). The shreds of evidence provided herein attest that puerarin efficiently ablates the Ihh-Nr2f2Bmp2 pathway and induces loss of uterine potential for decidualization.

One of the primary downstream regulators triggered by $\mathrm{P}_{4}$ is MAPK (Wetendorf \& DeMayo 2012). ERK $1 \frac{1}{2}$ is a member of the well-known MAPK pathway that has been implicated in the regulation of cellular proliferation and differentiation in multiple organ systems. Lee et al. (2013) demonstrated that ERK $1 \frac{1}{2}$ signalling was one critical pathway for ESC decidualization. ESC are inherently motile and invasive (Schwenke et al. 2013). The migratory and invasive capacity of endometrial ESC is increasingly recognized to contribute to the intense tissue remodelling associated with embryo implantation. Differentiating ESC actively promotes implantation by moving around and encapsulating the conceptus (Weimar et al. 2013). Multiple lines of evidence suggest a central role of ERK $1 / 2$ activation in this regard and one underlying mechanism involves the up-regulation of MMP2/MMP9 activity (Gellersen et al. 2010). This study clearly demonstrates that PN inhibited the activation of ERK $1 / 2$ in D6 pregnant uteri or hormone-stimulated hESC, down-regulated the endometrial expression of MMP9 and prohibited the migratory response of the decidualizing ESC in a dosedependent manner. It may be relevant in this context that puerarin is also reported to suppress proliferation of ESC acting via the suppression of the MAPK pathway (Cheng et al. 2012).

The induction of endometrial receptivity involves precisely choreographed crosstalk between the uterine stroma and epithelia. A plethora of regulatory signalling molecules has emerged, which control the chain of events; however, $\mathrm{P}_{4}$ and oestrogen (Simon et al. 2003) play the central roles. $P_{4}$ is essential for the establishment as well as maintenance of pregnancy in all species, while the requirement for oestrogen is species-specific. However, in mice and rats, both oestrogen and $\mathrm{P}_{4}$ are the absolute requirements. Recent evidence has suggested that concentration of oestrogen within a very narrow range determines the duration of the window of receptivity; at higher levels, oestrogen prematurely closes the implantation window (Dey et al. 2004). Oestrogen and $P_{4}$ exert their action by regulating gene transcription through binding to their cognate receptors, the ESR and PGR. There are two ESRs: ESR1 and ESR2, and two isoforms of PGR: PR-A and PR-B. The level of expression of these receptors varies among the cell types, as well as in concert with the progression of pregnancy and steroid hormone milieu (Dey et al.
2004, Wang \& Dey 2006). The essential $P_{4}$-regulated functions including implantation are mediated by PR-A (Wang \& Dey 2006), while PR-B is very faintly expressed in early pregnant rats (Sahlin et al. 2006). One of the major attributes of $\mathrm{P}_{4}$ action is to regulate the epithelial oestrogen action tightly. Importantly, $\mathrm{P}_{4}$ by acting via stromal PGR attenuates the oestrogeninduced epithelial gene expression (Kurihara et al. 2007). Thus, $P_{4}$ elicits stromal cell decidualization via Ihh-Nr2f2-Bmp2 signalling. The stromal $\mathrm{Nr} 2 f 2$ also facilitates epithelial remodelling and embryo attachment by suppressing epithelial oestrogen action by inhibiting the expression and activation (phosphorylation) of epithelial ESR (Kurihara et al. 2007). A previous report (Saha et al. 2012) from this laboratory demonstrated that puerarin treatment had no effect on the preimplantationphase serum levels of oestrogen and $\mathrm{P}_{4}$, although the endometrium showed the proliferative phenotype. In this study, we document that the altered endometrial response in the presence of consistent steroid hormone levels was a secondary consequence of the altered expression profile of the respective receptors in the stromal and epithelial compartments. It is significant to note that the compartment-wise analysis of receptors at protein levels showed down-regulated PR-A expression both in the epithelia and stroma. However, the two compartments discrepantly expressed the two ESR subtypes. The epithelia had an overexpression of ESR1 with no significant change in ESR2 expression while stroma showed no change in ESR1, but overexpression of ESR2. This observation may be extrapolated to suggest that attenuated PR-A expression, on the one hand inhibited the $\mathrm{P}_{4}$-mediated suppression of epithelial oestrogen activity, the crucial step in facilitating epithelial remodelling for embryo attachment, whilst at the other hand blocked the Ihh-Nr2f2-Bmp2 signalling pathway to terminate the epithelia-stroma crosstalk that organizes decidualization. Taken together, the failure of implantation is perhaps a consequence of puerarin effects at a multitude of uterine targets, as narrated in the working model (Fig. 9).

Thus, nanocapsulation allows efficient delivery of puerarin that reduces its $\mathrm{MED}_{100}$ to a significant extent. The translation of $\mathrm{MED}_{100}(75 \mathrm{mg} / \mathrm{kg}$ for D1 and D2) from rats to humans should not be a major concern, since the MED of a drug in humans $(\mathrm{mg} / \mathrm{kg})$ is approximately $1 / 7$ th of that of rats $(\mathrm{mg} / \mathrm{kg}$ ) (Bitto et al. 2009). Also, there should be no concern over the safety point of view as puerarin is well tolerated (Chung et al. 2009). Moreover, a recovery study conducted in our laboratory (unpublished observations) showed that the PN-treated rats restored their regular oestrus cycles within 7 to 12 days, and exposure of those rats to males resulted in normal mating followed by implantation and term pregnancy with normal litter size.

In summary, the array of events underlying the $\mathrm{PN}$ effects seem to be an adversely altered uterine 
expression of ESR subtypes and repression of PGR. This altered scenario indulges endless proliferation of the uterine luminal epithelia and distortion of the precisely choreographed stroma-epithelia crosstalk that effectively hinders the implantation process to block the establishment of pregnancy. PN, therefore, is envisioned as a likely candidate molecule that deserves further exploration for the development of non-steroidal EC formulation.

\section{Declaration of interest}

The authors declare that there is no conflict of interest that could be perceived as prejudicing the impartiality of the research reported.

\section{Acknowledgement}

This study was financially supported by the Council of Scientific and Industrial research and University Grants Commission, New Delhi, India in the form of a network project (BSC-0101) and Senior Research Fellowship to G S.

\section{References}

Achache H \& Revel A 2006 Endometrial receptivity markers, the journey to successful embryo implantation. Human Reproduction Update $\mathbf{1 2}$ 731-746. (doi:10.1093/humupd/dml004)

Bigsby RM, Cooke PS \& Cunha GR 1986 A simple efficient method for separating murine uterine epithelial and mesenchymal cells. American Journal of Physiology 251 E630-E636.

Bitto A, Altavilla D, Bonaiuto A, Francesca P, Minutoli L, Stefano VD, Giuliani D, Guarini S, Arcoraci V \& Squadrito F 2009 Effects of aglycone genistein in a rat experimental model of postmenopausal metabolic syndrome. Journal of Endocrinology 200 367-376. (doi:10.1677/JOE08-0206)

Cai J, Nelson KC, Wu M, Stemberg P Jr \& Jones DP 2000 Oxidative damage and protection of the RPE. Progress in Retinal and Eye Research 19 205-221. (doi:10.1016/S1350-9462(99)00009-9)

Cheng W, Chen L, Yang S, Han J, Zhai D, Ni J, Yu C \& Cai Z 2012 Puerarin suppresses proliferation of endometriotic stromal cells partly via the MAPK signaling pathway induced by 17 ß-estradiol-BSA. PLOS ONE 7 e45529. (doi:10.1371/journal.pone.0045529)

Chung HJ, Chung MJ, Houng SJ, Jeun J, Kweon DK, Choi CH, Park JT, Park KH \& Lee SJ 2009 Toxicological evaluation of the isoflavone puerarin and its glycosides. European Food Research and Technology 230 145-153. (doi:10.1007/s00217-009-1156-3)

Cullwell KR \& Curtis KM 2009 Use of contraceptive methods by women with current venous thrombosis on anticoagulant therapy: a systematic review. Contraception 80 337-345. (doi:10.1016/ j.contraception.2009.04.008)

Das SK 2009 Cell cycle regulatory control for uterine stromal cell decidualization in implantation. Reproduction 137 889-899. (doi:10.1530/REP-08-0539)

de Lanerolle P \& Paul RJ 1991 Myosin phosphorylation/dephosphorylation and regulation of airway smooth muscle contractility. American Journal of Physiology 261 L1-L14.

Dey SK, Lim H, Das SK, Reese J, Paria BC, Daikoku T \& Wang H 2004 Molecular cues to implantation. Endocrine Reviews 25 341-373. (doi:10.1210/er.2003-0020)

Dvorák K \& Bocan P 1980 The effect of hormonal contraceptives on the EEG. Ceskoslovenka Neurologie Neurochirurgie 43 71-77.

Farrar SC, Yenari J \& Gherman RB 2003 Emergency contraception: a "fire extinguisher" for unintended pregnancies. Primary Care Update for OB/ GYNS 10 284-287. (doi:10.1016/S1068-607X(03)00069-6)
Gellersen B, Reimann K, Samalecos A, Aupers S \& Bamberger AM 2010 Invasiveness of human endometrial stromal cells is promoted by decidualization and by trophoblast-derived signals. Human Reproduction 25 862-873. (doi:10.1093/humrep/dep468)

Glasser SR \& Julian J 1986 Intermediate filament protein as a marker of uterine stromal cell decidualization. Biology of Reproduction 35 463474. (doi:10.1095/biolreprod35.2.463)

Gu Y, Soares MJ, Srivastava RK \& Gibori G 1994 Expression of decidual prolactin- related protein in the rat decidua. Journal of Endocrinology 135 1422-1427. (doi:10.1210/endo.135.4.7925104)

Guha R, Chowdhury S, Palui H, Mishra A, Basak S, Mandal TK, Hazra S \& Konar A 2013 Doxorubicin-loaded MePEG-PCL nanoparticles for prevention of posterior capsular opacification. Nanomedicine (London) 8 1415-1428. (doi:10.2217/nnm.12.175)

Hamatani T, Daikoku T, Wang H, Matsumoto H, Carter MG \& Ko MSH 2004 Global gene expression analysis identifies molecular pathways distinguishing blastocyst dormancy and activation. PNAS 101 1032610331. (doi:10.1073/pnas.0402597101)

Hiremath SP, Badami S, Hunasagatta SK \& Patil B 2000 Antifertility and hormonal properties of the flavones of Striga orobanchoides. European Journal of Pharmacology 391 193-197. (doi:10.1016/S00142999(99)00723-2)

Improta-Brears T, Whorton AR, Codazzi F, York JD, Meyer T \& McDonnell DP 1999 Oestrogen-induced activation of mitogen-activated protein kinase requires mobilization of intracellular calcium. PNAS 96 4686-4691. (doi:10.1073/pnas.96.8.4686)

Jaffe AB \& Hall A 2005 Rho GTPases: biochemistry and biology. Annual Review of Cell \& Developmental Biology 21 247-269. (doi:10.1146/ annurev.cellbio.21.020604.150721)

Jefferson NW, Patisaul BH \& Williams JC 2012 Reproductive consequences of developmental phytoestrogen exposure. Reproduction 143 247-260. (doi:10.1530/REP-11-0369)

Kahlert S, Nuedling S, van Eickels M, Vetter H, Meyer R \& Grohe C 2000 Oestrogen receptor a rapidly activates the IGF-1 receptor pathway. Journal of Biological Chemistry 275 18447-18453. (doi:10.1074/jbc.M910345199)

Keyes PL \& Wiltbank MC 1988 Endocrine regulation of the corpus luteum. Annual Review of Psychology 50 465-482. (doi:10.1146/annurev. ph.50.030188.002341)

Krikun G, Mor G, Alvero A, Guller S, Schatz F, Sapi E, Rahman M, Caze R, Qumsiyeh M \& Lockwood CJ 2004 A novel immortalized human endometrial stromal cell line with normal progestational response. Endocrinology 145 2291-2296. (doi:10.1210/en.2003-1606)

Kurihara I, Lee DK, Petit FG, Jeong J, Lee K, Lydon JP, DeMayo FJ, Tsai MJ \& Tsai SY 2007 COUP-TFIl mediates progesterone regulation of uterine implantation by controlling ER activity. PLoS Genetics $\mathbf{3}$ e102. (doi:10.1371/journal.pgen.0030102)

Lee CH, Kim TH, Lee JH, Oh SJ, Yoo JY, Kwon HS, Kim YI, Ferguson SD, Ahn JY \& Ku BJ et al. 2013 Extracellular signal-regulated kinase 1/2 signaling pathway is required for endometrial decidualization in mice and human. PLOS ONE 8 e75282. (doi:10.1371/journal.pone.0075282)

Ling WY, Robichaud A, Zayid I, Wrixon W \& MacLeod SC 1979 Mode of action of dl norgestrel and ethinylestradiol combination in postcoital contraception. Fertility and Sterility 32 297-302.

Liu XJ, Jia Q, Wang CY \& Wang NL 2009 Study on absorption mechanism of puerarin and its nanoparticles across Caco-2 cell model. Journal of Chinese Medicinal Materials 32 1252-1255.

Lowry OH, Rosebrough NJ, Farr AL \& Randall RJ 1951 Protein measurement with the Folin phenol reagent. Journal of Biological Chemistry $193265-$ 275.

Marino M \& Galluzzo P 2008 Oestrogen receptor $\beta$ mediates the protective effects of oestrogen in colon cancer. Cancer Therapy 6 149-162.

Marino M, Galluzzo P \& Ascenzi P 2006 Oestrogen Signaling Multiple Pathways to Impact Gene Transcription. Current Genomics 7 497-508. (doi:10.2174/138920206779315737)

Mathieu ME, Saucourt C, Mournetas V, Gauthereau X, Thézé N, Praloran V, Thiébaud P \& Boeuf H 2012 LIF-dependent signaling: new pieces in the lego. Stem Cell Reviews 8 1-15. (doi:10.1007/s12015-011-9261-7)

Matsumoto K, Yamauchi N, Watanabe R, Oozono S, Kubota K \& Nishimura K 2009 In vitro decidualization of rat endometrial stromal cells. Cell Tissue Research 335 575-583. (doi:10.1007/s00441-008-0734-1)

McCracken JA, Custer EE \& Lamsa JC 1999 Luteolysis: a neuroendocrinemediated event. Physiological Reviews 79 263-323. 
Mendez MN 2002 Emergency contraception: a review of current oral options. Western Journal of Medicine 176 188-191. (doi:10.1136/ ewjm.176.3.188)

Parr MB \& Parr EL 1989 The implantation reaction. In Biology of the uterus, edn 2, pp 233-277. Eds RM Wynn and WP Jollie. New York and London: Plenum Medical.

Psychoyos A 1973 Hormonal control of ovoimplantation. Vitamines \& Hormones 31 201-256. (doi:10.1016/S0083-6729(08)60999-1)

Ramathal CY, Bagchi IC, Taylor RN \& Bagchi MK 2010 Endometrial decidualization: of mice and men. Seminars in Reproductive Medicine 28 17-26 (doi:10.1055/s-0029-1242989)

Riento K \& Ridley AJ 2003 Rocks: multifunctional kinases in cell behaviour. Nature Reviews Molecular Cell Biology 4 446-456. (doi:10.1038/nrm1128)

Riggs BL \& Hartmann LC 2003 Selective oestrogen-receptor modulators Mechanisms of action and application to clinical practice. New England Journal of Medicine 348 618-629. (doi:10.1056/NEJMra022219)

Saha P, Saraswat G, Chakraborty P, Banerjee S, Pal BC \& Kabir SN 2012 Puerarin, a selective oestrogen receptor modulator, disrupts pregnancy in rats at preimplantation stage. Reproduction 144 633-645. (doi:10.1530/ REP-11-0423)

Sahlin L, Masironi B, Akerberg S \& Eriksson H 2006 Tissue- and hormone dependent progesterone receptor distribution in the rat uterus. Reproductive Biology and Endocrinology 4 1-11. (doi:10.1186/1477-7827-4-47)

Salamonsen LA, Young RJ, Garcia S \& Findlay JK 1997 Mitogenic actions of endothelin and other growth factors in ovine endometrium. Journal of Endocrinology 152 283-290. (doi:10.1677/joe.0.1520283)

Savic R, Luo L, Eisenberg A \& Maysinger D 2003 Micellar nanocontainers distribute to defined cytoplasmic organelles. Science 300 615-618. (doi:10.1126/science.1078192)

Schwenke M, Knöfler M, Velicky P, Weimar CHE, Kruse M, Samalecos A, Wolf A, Macklon NS, Bamberger AM \& Gellerson B 2013 Control of human endometrial stromal cell motility by PDGF-BB, HB-EGF and trophoblast-secreted factors. PLOS ONE 8 e54336. (doi:10.1371/journal. pone.0054336)

Shukla S 1996 Post-coital contraceptive action of Pueraria tuberosa DC.extract in rats. Phytotherapy Research 10 95-99. (doi:10.1002/ (SICI)1099-1573(199603)10:2!95::AID-PTR699O3.0.CO;2-5)

Shukla S \& Mathur R 2002 Purareia tuberosa DC: contraceptive efficacy and toxicological profile. In Pueraria: the Genus Pueraria, edn 1, pp 85-97. Eds MW Keung. New York: Taylor and Francis, Inc.

Simon C, Dominguez F, Valbuena D \& Pellicer A 2003 The role of oestrogen in uterine receptivity and blastocyst implantation. Trends in Endocrinology \& Metabolism 14 197-199. (doi:10.1016/S10432760(03)00084-5)

Song H, Lim H, Das SK, Paria BC \& Dey SK 2000 Dysregulation of EGF family of growth factors and COX-2 in the uterus during the preattachment and attachment reactions of the blastocyst with the luminal epithelium correlates with implantation failure in LIF-deficient mice. Molecular Endocrinology 14 1147-1161. (doi:10.1210/mend.14.8.0498)

Suri SS, Fenniri H \& Singh B 2007 Nanotechnology-based drug delivery systems. Journal of Occupational Medicine and Toxicology 216. (doi:10.1186/1745-6673-2-16)

Swarnakar S, Ganguly K, Kundu P, Banerjee A, Maity P \& Sharma AV 2005 Curcumin regulates expression and activity of matrix metalloproteinases 9 and 2 during prevention and healing of indomethacin-induced gastric ulcer. Journal of Biological Chemistry 280 9409-9415. (doi:10.1074/jbc. M413398200)

Sylvestre M, Pichette A, Longtin A, Nagau F \& Legault J 2006 Essential oil analysis and anticancer activity of leaf essential oil of Croton flavens L. from Guadeloupe. Journal of Ethnopharmacology 103 99-102. (doi:10.1016/j.jep.2005.07.011)
Tamura I, Asada H, Maekawa R, Tanabe M, Lee L, Taketani T, Yamagata Y, Tamura H \& Sugino N 2012 Induction of IGFBP-1 Expression by cAMP Is associated with histone acetylation status of the promoter region in human endometrial stromal cells. Journal of Endocrinology 1535612 5621. (doi:10.1210/en.2012-1420)

Tan JL, Ravid S \& Spudich JA 1992 Control of nonmuscle myosins by phosphorylation. Annual Review of Biochemistry 61 721-759. (doi:10.1146/annurev.bi.61.070192.003445)

Tan J, Paria BC, Dey SK \& Das SK 1999 Differential uterine expression of oestrogen and progesterone receptors correlates with uterine preparation for implantation and decidualization in the mouse. Endocrinology $\mathbf{1 4 0}$ 5310-5321. (doi:10.1210/endo.140.11.7148)

Terkel J 1988 Neuroendocrine processes in the establishment of pregnancy and pseudopregnancy in rats. Psychoneuroendocrinology 13 5-28. (doi:10.1016/0306-4530(88)90004-2)

Tessier C, Deb S, Prigent-Tessier A, Ferguson-Gottschall S, Gibori GB, Shiu RP \& Gibori G 2000 Oestrogen receptors a and b in rat decidua cells: cell-specific expression and differential regulation by steroid hormones and prolactin. Endocrinology 141 3842-3851. (doi:10.1210/ endo.141.10.7734)

Wang H \& Dey SK 2006 Roadmap to embryo implantation: clues from mouse models. Nature Reviews Genetics 7 185-199. (doi:10.1038/ nrg1808)

Weimar CH, Macklon NS, Post Uiterweer ED, Brosens JJ \& Gellersen B 2013 The motile and invasive capacity of human endometrial stromal cells: implications for normal and impaired reproductive function. Human Reproduction Update 19 542-557. (doi:10.1093/humupd/ dmt025)

Wetendorf M \& DeMayo FJ 2012 The progesterone receptor regulates implantation, decidualization, and glandular development via a complex paracrine signaling network. Molecular Cell Endocrinology 357 108-118. (doi:10.1016/j.mce.2011.10.028)

Wu H, Lu C, Zhou A, Min Z \& Zhang Y 2009 Enhanced oral bioavailability of puerarin using microemulsion vehicle. Drug Development and Industrial Pharmacy 35 138-144. (doi:10.1080/03639040801973495)

Wooding FBP \& Flint APF 1994 Placentation. In Marshall's Physiology of Reproduction, edn 4, pp 233-460. Eds GE Lamming. London: Chapman \& Hall.

Yee MG \& Kennedy GT 1988 Stimulatory effect of prostaglandins upon endometrial alkaline phosphatase activity during the decidual cell reaction in rat. Biology of Reproduction 38 1129-1136. (doi:10.1095/ ?biolreprod38.5.1129)

Yu A, Wang H, Wang J, Cao F, Gao Y, Cui J \& Zhai G 2011 Formulation optimization and bioavailability after oral and nasal administration in rabbits of puerarin-loaded microemulsion. Journal of Pharmaceutical Sciences 100 933-941. (doi:10.1002/jps.22333)

Zhao LX, Liu AC, Yu SW, Wang ZX, Lin XQ, Zhai GX \& Zhang QZ 2013 The permeability of puerarin loaded poly(butylcynoacrylate) nanoparticles coated with polysorbate 80 on the blood-barrier and its protective effect against cerebral ischemia/reperfusion injury. Biological and Pharmaceutical Bulletin 36 1263-1270. (doi:10.1248/bpb.b1200769)

Received 20 January 2016

First decision 12 February 2016

Revised manuscript received 4 March 2016

Accepted 24 March 2016 